Portland State University

PDXScholar

7-1-1992

\title{
Early-Return-to-Work Programs: An Exploratory Study of the Effects of Program Policies and Practices on Organizational Outcomes
}

Lorrie L. Riat

Portland State University

Follow this and additional works at: https://pdxscholar.library.pdx.edu/open_access_etds

Part of the Psychology Commons

Let us know how access to this document benefits you.

Recommended Citation

Riat, Lorrie L., "Early-Return-to-Work Programs: An Exploratory Study of the Effects of Program Policies and Practices on Organizational Outcomes" (1992). Dissertations and Theses. Paper 4423.

https://doi.org/10.15760/etd.6301

This Thesis is brought to you for free and open access. It has been accepted for inclusion in Dissertations and Theses by an authorized administrator of PDXScholar. Please contact us if we can make this document more accessible: pdxscholar@pdx.edu. 
AN ABSTRACT OF THE THESIS OF Lorrie L. Riat for the Master of Science in Psychology presented July 1, 1992 .

Title: Early-Return-to-Work Programs: An Exploratory Study of the Effects of Program Policies and Practices on Organizational Outcomes.

APPROVED BY THE MEMBERS OF THE THESIS COMMITTEE:

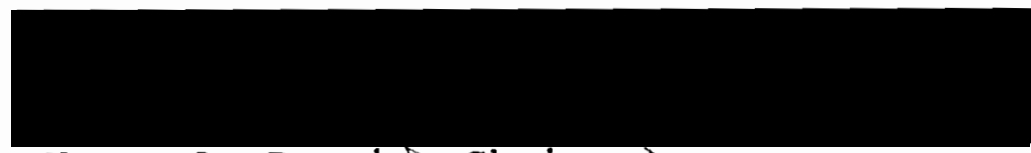

Nancy A. Perrinishair

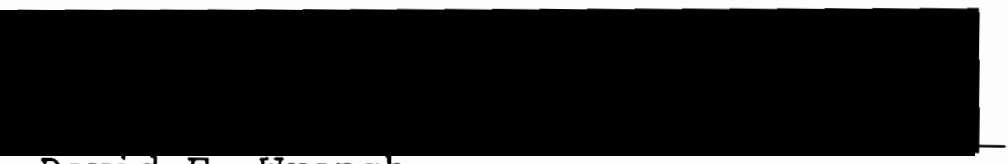

David F. Wrench

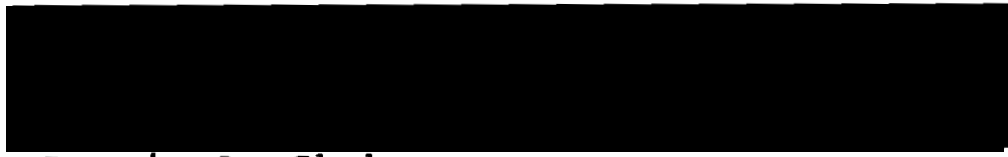

Laurie A. Skokan

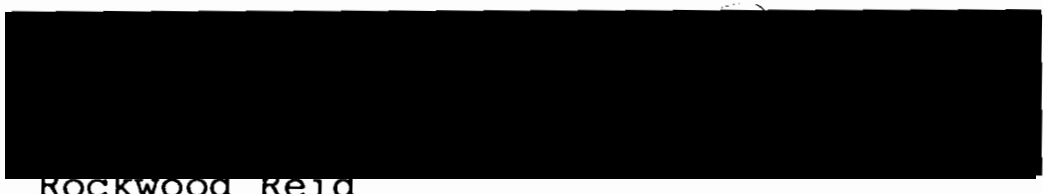

Rockwood Rela

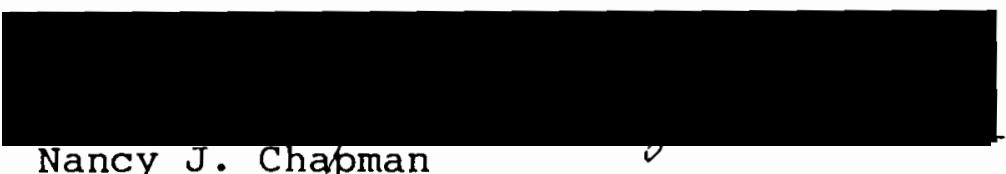

Early-return-to-work (ERTW) programs for injured workers are a relatively new development. While it is widely believed that such programs are the primary means of controlling workers' compensation costs after an injury has 
occurred, little research has been done on how these programs accomplish that end. This thesis is an exploratory examination of the factors involved in ERTW programs and the relationship between components of ERTW programs for injured workers and organizational outcomes, specifically the cost of medical care and wage reimbursement associated with workers' compensation claims.

To examine the above relationship, 202 organizations in Portland, Oregon were surveyed by telephone about their policies and practices pertinent to injured workers. Outcome data on each organization was then obtained from the State of Oregon Bureau of Labor and Industries.

Exploratory factor analysis revealed five factors from the survey data - a non-ERTw approach, organizations' perceptions of ERTW, extent of ERTW, communication about the ERTW program, and written formalization for dealing with injured employees. This solution accounted for 47.228 of the total variance. Confirmatory factor analysis on a holdout sample revealed that the initial structure was quite stable, but added an additional factor - that of using regular wage for light duty positions. However, follow-up analyses, using covariance structural modeling suggested two additional factors, each of which had only one variable loading on it. They were an early-return-to-work (ERTW) factor and a regular wage factor. Confirmatory factor analysis fit indices for that model were as follows: $\mathrm{x}^{\alpha}(122)=245.55(\mathrm{p} .=0.000)$, Goodness of Fit Index $=$ 
0.808 , Adjusted Goodness of Fit Index $=0.731$, and Root Mean Square Residual $=0.166)$.

When data from the state of Oregon Bureau of Labor and Industries was added, two additional factors were found. The first was identified as the people statistics factor, which involved variables dealing with the number of currently open claims, the number of non-disabling claims for the year, and the number of reopened claims. The second factor was identified as the dollars cost factor. The variables that loaded on it were the median cost of medical claims and the median cost of wage reimbursement.

Regression analyses were conducted to examine ability to predict the change in median medical and wage reimbursement costs from 1985 to 1990. Results suggested that all of the variables together had a significant ability to predict the change in median medical costs $\left(\mathrm{R}^{2}=0.296, \mathrm{p} .=0.003\right)$ and that the variables related to the extent of the ERTW program factor, organizations' perceptions of ERTW factor, and regular wage factor was offered were able to predict a significant amount of variance in the change in median medical costs.

All of the variables together also had a significant ability to predict the change in median wage reimbursement costs over time $\left(\mathrm{R}^{2}=0.243, \mathrm{p} .=0.032\right)$. However, none of the groups of variables associated with the factors was able to significantly predict the change in 
median wage reimbursement costs over time.

Also examined were organizations' preferences in programs and policies for both those organizations with the best performance (in terms of both medical and wage reimbursement workers' compensation costs) over time and organizations with the worst performance over time (again, in terms of both medical and wage reimbursement workers' compensation costs). 
EARLY-RETURN-TO-WORK PROGRAMS : AN EXPLORATORY STUDY OF THE EFFECTS OF PROGRAM POLICIES AND PRACTICES ON ORGANIZATIONAL OUTCOMES

$$
\text { by }
$$

LORRIE L. RIAT

A thesis submitted in partial fulfillment of the requirements for the degree of

\author{
MASTER OF SCIENCE \\ in \\ PSYCHOLOGY
}

Portland State University

1992 
TO THE OFFICE OF GRADUATE STUDIES:

The members of the Committee approve the thesis of Lorrie L. Riat presented July 1, 1992.

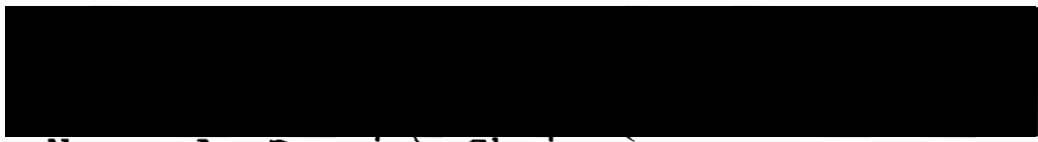

Nancy A. Perrind Chair

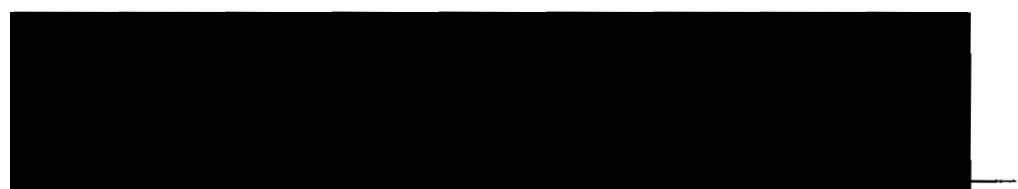

David F. Wrench

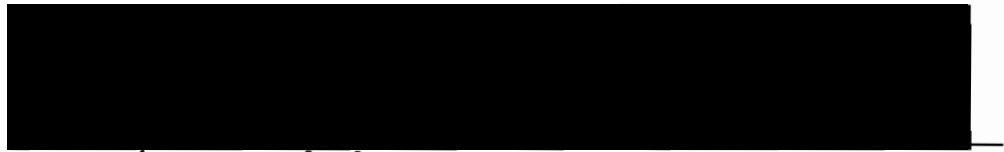

Laurie A. Skokan

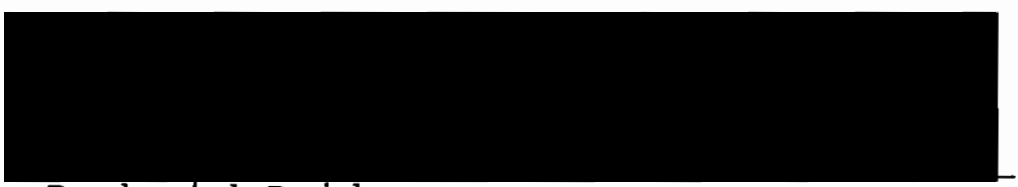

Rockwood Reid

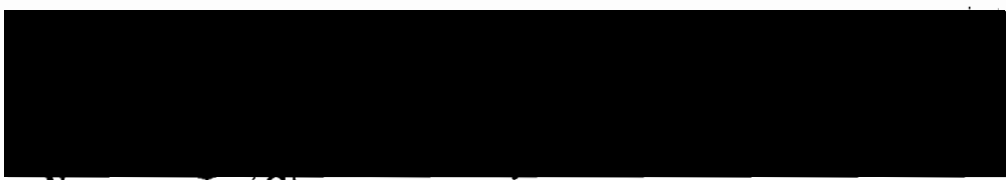

Nancy $J .7$ Chapman

APPROVED :

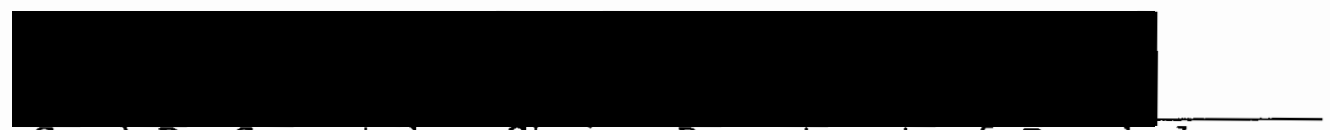

cord B. Sengstake, Chair, Department of Psychology

c. Wllliam Savery, Interim vłze provost for Graduate studies and Research 


\section{DEDICATION}

This thesis is dedicated to steven W. Riat who has been incredibly patient and supportive throughout the insanity of graduate school as well as to my parents, Carol and Dennis Larson, who have always encouraged and supported my efforts to obtain an education. 
TABLE OF CONTENTS

PAGE

LIST OF TABLES

INTRODUCTION

Background . . . . . . . . . . . . . . 1

The Workers' Compensation System . . . . . . . . 3

The Insurers . . . . . . . . . . . . . 6

The Worker . . . . . . . . . . . . 6

The Employer . . . . . . . . . . . . . . 8

Return-to-Work . . . . . . . . . . . . 10

Early-Return-to-Work (ERTW) Programs . . . . . . 11

Research Structure and Goals . . . . . . . . .14 METHOD . . . . . . . . . . . . . . . . . . . . . . .

Subjects . . . . . . . . . . . . . . . 16

Materials. . . . . . . . . . . . . . 16

Procedure. . . . . . . . . . . . . . . 19 RESULTS. . . . . . . . . . . . . . . . 20

Descriptive Statistics . . . . . . . . . . 20

Exploratory Factor Analysis. . . . . . . . . . 22

Confirmatory Factor Analysis Process/Indices . . . .28

Confirmatory Factor Analysis without State Variables.............. . . . 30

Confirmatory Factor Analysis with State

Variables............... . . . 31 
PAGE

Multiple Regression. . . . . . . . . . . . .33

A Comparison of High versus Low Performing

Organizations (In Terms of Workers'

Compensation Costs) . . . . . . . . . .38

DISCUSSION • • • • • • . . . . . . . . . . . .69

Descriptive Findings . . . . . . . . . . .69

Exploratory Factor Analysis Findings . . . . . . .71

Confirmatory Factor Analysis Findings. . . . . . .74

Regression Findings. . . . . . . . . . . . .76

Findings on the Comparison of High versus

Low Performing Organizations. . . . . . . .78

Limitations of this Study. . . . . . . . . . . . .

Problems with the Survey Instrument. . . . . . .80

Recommendations for Further Research . . . . . .83

Recommendations for Organizations. . . . . . . . 86

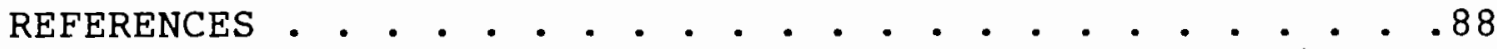

APPENDIX ...................... . . 90 


\section{LIST OF TABLES}

TABLE

PAGE

I Descriptive Statistics for the Survey

Questions . . . . . . . . . . . 4 45

I Simple Correlations between Survey

Questions . . . . . . . . . . . 48

II Simple Correlations between the Survey

Questions and the Organizational

Outcome Variables . . . . . . . . . 51

IV Rotated Factor Pattern for Five-Factor

Solution. • . • . . . . . . . . 52

V Statistics for Rotated Factor Pattern for

Five-Factor Solution. . . . . . . . 54

VI Inter-Factor Correlations for the Rotated

Solution. . . . . . . . . . . 55

VII Simple Correlations between the Survey

Questions and the Change in Medical

Costs and the Change in Wage

Reimbursement Costs . . . . . . . 56

VIII Results of Regression to Predict Change in

Medical Costs from 1985 to 1990, Using

All Program Components. . . . . . . 57 
IX Results of Regression to Predict Change in Medical Costs from 1985 to 1990, Using the Variables that Make Up Each Factor. . . . . . . . . . 58

$x \quad$ Results of Regression to Predict Change in Wage Reimbursement Costs from 1985 to 1990, Using All Program Components. . . 60 XI Results of Regression to Predict Change in Wage Reimbursement Costs from 1985 to 1990, Using the Variables that Make Up Each Factor. ........... 61

XII A Comparison of High versus Low Performing Organizations on Wage Reimbursement Costs............... . 63

XIII A Comparison of High versus Low Performing Organizations on Medical Costs. . . . 66 


\section{INTRODUCTION}

Early-return-to-work (ERTW) programs are recognized as the primary means of controlling workers' compensation costs once an injury has occurred. Such programs have been shown to be beneficial to all parties involved - the worker, the employer, and the insurer. However, because these programs are relatively new, no research has been done to examine the relationships of the different components of ERTW programs on organizational outcomes such as average medical costs and average cost of wage reimbursement per claim. This thesis uses exploratory and confirmatory factor analysis and regression analyses to explore these questions.

\section{BACKGROUND}

Workers' compensation legislation was created on a state-by-state basis between the years 1911 and 1949 to provide income, medical care, and rehabilitation assistance without regard to fault to workers who are injured in the course of performing their jobs. While the need for such programs is obvious, the form which they should take is difficult to determine.

After 50 - 80 years of existence, there is little doubt current systems are experiencing very serious problems nationwide. Richard Fein, acting president of the National 
Council of Compensation Insurance, has stated that the current workers' compensation system will either be replaced by an improved system or will fall into ruin (Brown, 1990). William Bolton, CEO of an independent insurance brokerage in California, believes that in many states, the workers' compensation system is so ineffective it's actually detrimental to workers. James Ellenberger, assistant director of Occupational Safety, Health, and Social Security for the AFL-CIO takes a slightly more conservative position. He expresses the opinion that unless substantial improvements occur shortly, at the very least, a Federal law mandating minimum standards may be necessary (Sheridan, $1990)$.

Employers have begun to recognize that controlling the cost of their workers' compensation claims is vital to the financial health of their organizations. In addition, there is now greater recognition that losing a trained, skilled employee, even temporarily, creates organizational costs such as those incurred in training a replacement, lost productivity, and decreased morale of other employees.

Employees who are injured on the job face a number of obstacles in using workers' compensation. Financial compensation for disabling injuries is largely unstandardized, often has not kept pace with the rising cost of living, and in too many cases, is obtained only after long legal battles. Rehabilitation services are not always available who could benefit from them and often come too 
long after onset of disability to provide optimum outcomes. obtaining benefits is usually dependent on an ability to make one's way through a bureaucratic maze. In short, the systems are inadequate and difficult to use.

\section{THE WORKERS' COMPENSATION SYSTEM}

Workers' Compensation legislation was designed to provide medical care, rehabilitation, and income assistance to workers who have been injured on the job or stricken with an occupationally related disease. Most systems are based on two types of claims - temporary disability and permanent disability. Benefits for temporarily disabling injury claims provide a weekly income based on the amount of wages earned on the job, as well as medical care and, where appropriate, rehabilitation assistance. In these cases, it is expected that the employee will recover and return to work. Benefits for a permanently disabling injury usually include medical care and some form of monetary settlement. In cases where the injury is considered to have caused permanent total disability, the injured worker is not ever expected to return to work, but benefits may be provided for life or for some pre-determined shorter period of time (based on the type of injury) and depending on the specific legislation. Injured employees may also be classified as having a partial permanent disability. In these instances, the individual is expected to be left with some permanent loss of functioning, but is still expected to be able to 
work (although not necessarily in his/her previous position). Again, income assistance, medical care, and (sometimes) rehabilitation are provided. In the case of a job-related fatality, limited assistance with burial costs is generally provided and dependents of the deceased receive some form of financial support or settlement.

National statistics support the idea that serious problems exist within the workers' compensation systems. For example, in 1989 the combined ratio of payout to premium was 120.18 , meaning that for every premium dollar collected, workers compensation insurers paid $\$ 1.20$ in benefits and associated costs. Each year, 569,000 new cases enter the workers' compensation system. Nearly half of those injured workers will never return to work and another $10 \%$ will take 3 years to go back to work (Engle Beam, 1987). These statistics suggest that the demands on the system will continue to grow.

Oregon is no exception. The state is burdened with a workers' compensation system which has resulted in some of the highest costs in the country (in 1988, Oregon employers paid the eighth highest workers' compensation premiums in the nation, according to the Oregon Department of Insurance and Finance) while doing an ever-poorer job of helping injured workers return to work (Mapes, 1990) and is now experiencing "universal criticism" (Mapes, 1990, p. B1). Herbert Aschkenasy, board chairman of SAIF Corp., calls Oregon's workers' compensation system "scandalous" (Mapes, 
p. A24) and adds that "It's not only expensive, it's not even effective." (Mapes, 1990, p. A24). Workers in this state have the highest rate of total claims in the country over 15 per 100 workers (Mapes, 1990). Recent statistics indicate that the number of permanent, partial disability cases is increasing (these make up a large portion of the most expensive cases). A record percentage of workers are saying that their injuries have left them permanently damaged, and the average amount of time off the job has increased from just 10 years ago (Mapes, 1990). For example, in 1988, there were 43,660 claims closed with an average of 87 lost days per case and an average total cost of $\$ 8,371.00$ per claim (statistics from Oregon Department of Insurance and Finance). A comparison of Oregon's Workers' Compensation System with that of wisconsin's (which has been called "the envy of other states" by Sen. Jerome Van Sistine, chair of the Wisconsin Legislature's Committee on Labor, Business Insurance, Veterans and Military Affairs, according to Mapes [1990, p. B4]) gives a clearer picture of what can be accomplished. In 1988, Oregon's system covered 1,099,900 workers, had 153,137 claims and paid out $\$ 578.4$ million (Oregon Department of Insurance and Finance, 1990). On the other hand, in the same year, Wisconsin's system covered 2,121,104 workers, had 76,917 claims and paid out $\$ 209$ million (State of Wisconsin, 1990 as cited by Mapes, 1990). Because of the severe problems being experienced by the Oregon workers' compensation system, Ex-Governor Neil 
Goldshmidt convened a committee of labor and business, hoping that without representatives of the legal, medical, and insurance communities, some agreement on reforms could finally be reached.

The effects of an ineffective workers' compensation system are felt by everyone involved - insurers, employers, injured workers, and their families.

\section{THE INSURERS}

Insurers obviously cannot survive indefinitely when they are experiencing combined ratios at or above 100\%. If this trend continues, the number of firms who are willing and able to offer workers' compensation insurance will decline drastically. Some firms may choose to withdraw from the workers' compensation market and concentrate on other markets while others that focus soley on offering workers' compensation insurance may cease to exist altogether.

\section{THE WORKER}

Injured employees also suffer when they are unable to return to work quickly. Many experience financial difficulty due to loss of income, but other consequences may be even more harmful. In our society, adults are defined in large part by the work they do. When injured employees lose their working identity and are forced to replace it with some form of a "disabled person" identity, they are likely to experience emotional stress. Kelvin 
(1981) suggests that the loss of the work role that is quite frequently an integral part of peoples' values, self-image and life-structure, can be a threat to psychological health. Furthermore, the label "disabled person" carries with it a very low status in this society. Hood and Downs (1985) state that returning disabled persons to activity can increase both self-esteem and prestige and help to mitigate the adverse impact of any lasting disability.

Besides the injured worker, the family is also likely to suffer as a result of prolonged homebound recuperation periods (or permanent inability to work). The stress involved in such a major change in lifestyle will likely affect each member of the family system in some way. For example, Verslyus (1980) states that even very stable families may experience distress as a result of disabilityrelated unemployment.

There is also some possibility that an injured employee may develop some form of "disability dependence". Hood and Downs (1985) state that the processes for determining eligibility for disability benefits tends to support dependence on the system. Walker (1989) reported a small but consistent number of cases, which he called "perpetual patients", who are off work for significantly longer periods of time than others with similar injuries. He attributed the cause to psychological problems. Taylor (1989), on the basis of his review of research involving return to work after back surgery, concluded that among the primary 
determinants for return in these cases is the "renewal of psychological determination to become productive" (p. 85). He discusses a deconditioning syndrome which results from a tendency for back-injured workers to be overly cautious about protecting their backs. Hanson-Mayer (1984) suggests that psychological factors which contribute to "worker's disability syndrome" are best dealt with early in the recovery process. In a sample of 200 English workers' compensation claimants, Cornes, Bochel, and Aitken (1986) report that there was some suspicion of psychological reasons for failure to return to work in 138 of their sample.

\section{THE EMPLOYER}

Employers also absorb some of the high cost of the workers' compensation system. Due to skyrocketing costs, workers' compensation insurance has recently become a major part of the cost of doing business. Because an organization's yearly premiums are computed in part on the basis of past claims costs, every dollar paid out because of an injury to one of their employees will cost them money in the future. By 1987, national workers' compensation costs had soared to $\$ 120$ billion (Lucas, 1987), including both those costs paid by companies, and those paid by the government. Premiums have been climbing steadily. According to the U.S. Social Security Administration, premiums have risen from a total of 22.2 billion dollars in 
1980 to a total of 34.1 billion dollars in 1986. Despite skyrocketing increases in premiums, workers' compensation insurers have been experiencing losses (Brown, 1990). Because of this trend, insurers have been ever more cautious about what companies they choose to insure. Mapes (1990) reported that SAIF was attempting to turn around their financial situation in part by dropping many of the small businesses that they previously insured and that many of those businesses can not afford to obtain workers' compensation coverage elsewhere. This means that the availability and cost of workers' compensation insurance is in some cases making the difference between an ongoing business and a business that no longer exists.

The current workers' compensation system creates other problems for employers. When an employee who has the capacity to return to their previous position does not do so, the cost of hiring and training a replacement may run into thousands of dollars. Another less recognized consequence of unnecessarily losing an employee to an injury comes in the form of a likely blow to other employees' morale if they perceive that the organization does not care about its individual employees. One approach to these situations involves modifying the position to accommodate the employee's physical limitations. Another partial solution is to put disabled employees in other positions within the company, where they can put knowledge learned in their previous position to use. This is likely to result in 
some cost saving to the employer, as well as to provide an employment solution to a partially disabled person who would likely have difficulty obtaining a new job.

\section{RETURN-TO-WORK}

There are a number of reasons for the distressed state of workers' compensation systems. Engle Beam (1987) provides a useful discussion of this topic. She reports that the system often discourages disabled workers from returning to work. (Livneh [1982] concurs with this statement, reporting that disabled workers who could return to work are often prevented or delayed from doing so.) The percentage of injured workers who will eventually go back to work is not particularly high. Of the 569,000 workers who incur some form of disability each year due to a physical injury while working, almost half will never return to work. Another 10 percent of those workers will not return to work for three years. In addition, the current workers' compensation system frequently requires disabled workers to prove that they are unable to work, whether they wish to be employed or not. Employers' attitudes toward disabled employees have not generally been helpful. Employees who sense that their employer will not be pleased to have them back when they are unable to perform their previous duties fully are less likely to return to work. These factors work together to encourage the development of a dependency orientation in the worker. Hanson-Mayer (1984) calls this 
"workers" disability syndrome", and reports that this psychological state may become the primary obstacle preventing the worker from returning to work. Once that orientation has developed, the likelihood that an employee will return to work is decreased substantially.

Research by the state of Oregon supports the importance of returning to work as soon as possible after the occurrence of an injury. Findings indicate that after six months off work, an employee has only a 508 chance of returning to work while after one year off work, chances of returning to work drop to less than $10 \%$ (Oregon Department of Insurance and Finance, 1989). In their review of the return-to-work literature, Hood and Downs (1985) state that evidence indicates that establishing return to work objectives as early as possible in injured workers' recovery processes helps more workers return to work sooner and more often to their previous jobs.

\section{EARLY-RETURN-TO-WORK (ERTW) PROGRAMS}

As organizations have watched the cost of their worker's compensation insurance rise dramatically, and as insurers have begun experiencing serious losses, both parties have begun to search for ways to control these costs. Two methods have been identified. First, companies can work to prevent injuries before they occur through safety/risk management programs. Second, once an injury has occurred, a company can take a proactive approach to keeping 
the cost of that specific injury low through ERTW programs. SAIF (1990) reports that an average of $\$ 3500$ is saved after an employee is placed in an ERTw program. The best strategy for an organization involves implementing both types. However, ERTW programs and their effects on organizational outcomes will be the topic of this research project.

ERTW programs involve the use of several strategies to cut the cost of current injuries (and in the long run, to lower the cost of worker's compensation premiums). These are as follows:

1) Stay in contact with injured workers as they recover to let them know that the company cares about their progress and wants them back (some care needs to be taken not to use an adversarial approach)

2) Identify or create light duty jobs so that injured workers can, with their doctors' approval, return to work in jobs that fit their current physical capabilities, rather than waiting until the injured employee is 1008 recovered (which may take much longer, and in the case of permanently disabling injuries, will never occur)

3) Analyze and record the specific physical demands of each job in the organization. This information helps the treating physician make decision about readiness for light duty work and about when the employee's physical capacity tolerances will allow them to return to their previous jobs

4) Provide monetary incentives for an injured employee to return to work early. This strategy suggests that the 
injured employee should be able to earn more than their workers'compensation payments by working at least part time.

5) In addition, it is believed that such programs also help to reduce fraudulent claims because the pay-off for "faking" an injury is removed - the would-be vacationer is still required to work.

Case studies strongly suggest that these programs are an effective way to decrease workers'compensation costs. For example, Burlington Northern developed an aggressive ERTW program and reported being able to cut the number of employees who were unable to return to work due to disability in half over a 21 month period (Lucas, 1987). Alcoa created a program which involved bringing injured employees back to work at the point that they are able to do some job at some level. They report saving more than 20 percent of their expected 1983 workers compensation premiums (Wardrop, 1984). One unidentified Oregon company experienced dramatic benefits after instituting an ERTW program and other loss prevention measures. During the previous two-year period, they had experienced 35 claims which generated over 2,400 days of lost time and had a total claims cost of over $\$ 330,000$. A year later, they had only one time loss claim with a total cost of $\$ 5,000$ (SAIF, 1990). Consolidated Freightways also reported significant improvements in both the number of time loss injuries and in the frequency of injuries after beginning their ERTW program. In 1986, their Illinois plant had 120 injuries, 66 
of which resulted in lost time. In 1987, with program implemented, they had just over 70 injuries with only 44 resulting in lost time. And by August of 1988, they had experienced approximately 50 injuries with just 21 cases resulting in time loss.

Other researchers have examined the benefits of ERTW for the involved employees. (See Hood and Downs, 1985 for a comprehensive review of this literature.) They concluded that early intervention strategies not only reduce the cost of disabilities but also have the ability to reduce both the physical and psychosocial suffering of the injured worker. SAIF has found that injured workers who return to work via an ERTW program actually recover from their injuries more quickly (SAIF, 6/90). This finding is likely due to the fact that modified work serves as a "work hardening" process which, when well conceived, may provide excellent therapy for the injury. This data suggests that ERTW programs are a win-win solution for dealing with on the job injuries.

\section{RESEARCH STRUCTURE AND GOALS}

Because the concept of ERTW is quite new, little research has been done on it, either in terms of the underlying factors involved or in terms of the effects of various organizational policies and practices on organizational outcomes (i.e. number of open claims, number of non-disabling claims, number of reopened claims, and 
average medical and wage replacement cost of claims). This research examined the underlying structure of ERT' and the effect of variation in ERTW programs' policies and practices on those organizational outcomes. To accomplish this, organizations in the Portland Metropolitan area were contacted by phone and surveyed regarding their policies and practices on returning injured employees to work and the Oregon Bureau of Labor and Industries provided outcome data for the surveyed organizations.

The goals of this study were as follows:

1) Create a preliminary model describing the structure of ERTW programs (based on corollary data)

2) Discover which components of ERTW programs make for effective programs by examining the ability of the presence or absence of the various components to predict a decrease in organizational outcome variables over time (when adjusted for inflation)

3) Examine differences in the components of ERTW programs between organizations with the best performance in controlling workers' compensation medical and wage reimbursement costs over time. 
METHOD

SUBJECTS

Subjects were 202 organizations from washington, Multnomah, and Yamill counties, generally with at least 50 employees (although there were a few exceptions to this). No attempt was made to draw a representative sample from across the range of industries, but instead, the emphasis was on surveying organizations whose employees experience injuries with at least some regularity. The only industry which was nearly eliminated based on this criteria was that of Finance, Insurance, and Real Estate. This approach was chosen as the research focus required injury data. Twenty-nine of the organizations were also surveyed previously during the pre-testing phase of the questionnaire.

\section{MATERIALS}

A list of companies in the Oregon Tri-County area with over 50 employees was obtained from the Oregon Bureau of Labor and Industries. The listing contained information on employer name, address, identification number, and approximate number of employees, broken down by type of industry. This list was used to choose those organizations 
who dealt with workers' compensation that at least occasionally answered their phone (rather than leaving it forwarded to voice-mail continuously), they had some history of on-the-job injuries, and they were willing to participate in the survey.

In addition, a brief list of companies (approximately 12) with ERTW programs was obtained from SAIF Corp. It was used to contact a number of companies who are known to have in place ERTW programs. A few of those companies had slightly fewer than 50 employees.

The return to work survey used in the study asks 19 questions about the organization's policies and practices regarding workers who have been injured on the job as well as 3 questions about organizational characteristics (see Appendix A). An additional question was included to try to assess the rate of injury. However, that data was not analyzed as a large number of organizations were reluctant to discuss those figures and it was believed that most of those who were willing to discuss them were not able to provide accurate data.

The questionnaire was pre-tested on 50 organizations. Modifications were made based on the results of the pretest and an interview with a ERTW expert at SAIF Corporation. The current version of the questionnaire was modified to to include:

1) a question about the proportion of employees who's jobs are covered by light duty alternatives when they have 
been injured,

2) a 1 to 5 scale assessment of the organization's dedication to the use of ERTW and/or modified or light duty work,

3) a question regarding whether the employees sign a form stating that they understand and accept the ERTW policy and the responsibilities it gives them,

4) a question assessing the amount of training organizational members have had in the use of ERTW procedures.

Response results were excellent and showed the survey to be easily comprehensible to the respondents. Fewer than 10 organizations declined to participate.

Data on dependent variables was obtained from the state of Oregon Department of Labor and Industries for 1990 and 1985. Information on the following variables was used:

1) number of non-disabling injuries

2) median medical cost for closed claims

3) median wage reimbursement cost for closed claims

4) number of open claims

5) number of reopened claims

The median was used as an indicator of organizational outcomes because the data do not produce a normal distribution, but are subject to extreme outliers, which is to be expected when some of the financial settlements are determined by the outcome of court cases and when settlements for injury types which do not have a predetermined settlement amount can vary widely from case to case. One drawback of these outcome variables is that 
each of those that involves looking at the "number of..." has a confound with organizational size.

Attempts to obtain information on the average number of days lost per injury, on the number of disabling claims, and on the medical and wage reimbursement costs of disabling claims from the organizations themselves resulted in data of questionnable reliability/validity. For that reason, no analyses were done on that data.

\section{PROCEDURE}

Organizations were surveyed by telephone. Respondents held a wide variety of positions within their respective organizations - these positions included risk analysis, safety specialist, occupational health nurse, office manager, organizational manager, early-return-to-work specialist, and the person who dealt with the workers' compensation paperwork. Dependent variable data from the Oregon Bureau of Labor and Industries was obtained on each of the companies who participated in the survey. The two sets of data were then combined for analysis. The set of 202 cases was randomly divided into two separate files, one to be used for the exploratory analysis, and one to be used for the confirmatory analysis. This was done by assigning all of the even-numbered cases to one file and all of the odd-numbered cases to another file. 


\section{RESULTS}

\section{DESCRIPTIVE STATISTICS}

Descriptive statistics that characterize the sample of 202 organizations are presented below:

1) The mean number of employees in the organizations surveyed was 879.33 with a standard deviation of 1,662.6. This variable was not normally distributed; the maximum number of employees was 10,000 and the minimum was 20 . The median number of employees in the surveyed organizations was 247.5 .

2) Twenty-four percent of the organizations reported being self-insured, 26 percent reported that their workers' compensation insurer was Liberty, and 17 percent reported SAIF as their workers compensation insurer. Two percent of survey respondents did not know who the organization's workers' compensation insurer was. The remaining 31 percent of respondents reported being insured by a wide variety of insurance companies.

3) Forty-seven percent of the organizations reported having at least some union members. Of those reporting some union membership, the mean percentage of union employees was 75.28 and the standard deviation was 27.6 .

Descriptive statistics for the questions in the survey 
are presented in Table I. Simple correlations between the survey variables are presented in Table II (these were used only for descriptive purposed, not for interpretation). Both of these tables are based on an $\mathrm{N}$ of 172. These data are from the organizations for which matching variables from the Oregon records were available.

Descriptive statistics on the data obtained from the State of Oregon Bureau of Labor and Industries (for 1990) are as follows:

1) Number of reopened cases had a mean of 0.42 and a standard deviation of 0.99 . The minimum number of reopened cases was 0 and the maximum was 6 . There was very little variance in this variable - over 758 of the organizations had no reopened cases.

2) Number of non-disabling claims for 1990 had a mean of 8.38 and a standard deviation of 15.74. The minimum number of non-disabling claims was 0 and the maximum was 125 .

3) Number of open claims had a mean of 2.22 and a standard deviation of 4.90 . The minimum number of open claims was 0 and the maximum was 47 .

4) Median cost of medical claims had a mean of $\$ 2,014.12$ and a standard deviation of $\$ 3,199.61$. The minimum was $\$ 0$ and the maximum was $\$ 25,897$.

5) Median cost of wage reimbursement payments had a mean of $\$ 1,301.69$ and a standard deviation of $\$ 2,872.97$. The minimum was $\$ 13$ and the maximum was $\$ 32,292$. 
The simple correlations between the survey questions and the outcome variables (from the State of Oregon, Bureau of Labor and Industries) are given in Table III. Three of the survey questions had significant (positive) correlations with the number of open claims organizations had. They were whether the organization had a written return-to-work policy, whether they tell their new employees about their ERTW program, and the amount of training people in the organization had on ERTW programs. The number of nondisabling claims had significant (positive) correlations with four survey questions. Those variables were whether the organization had a written return-to-work policy, the amount of training people in the organization had obtained on ERTW programs, the percentage of injuries in which ERTW is used, and the level of dedication to the ERTW program. The number of reopened claims had three survey variables that were significantly related - whether the organization had a written return-to-work program was positively correlated with it as was the amount of ERTW training. These correlations were not in the expected direction. However, offering regular wage to employees on light duty was negatively correlated with reopen claims.

\section{EXPLORATORY FACTOR ANALYSIS}

To begin, the 202 cases were divided into two groups by putting all cases with even identification numbers in one file and all cases with odd identification numbers in 
another file. All exploratory work was done on one set. Then the second set of data was used to confirm the final models found in the exploratory analyses.

Because no strong hypotheses about which variables were related existed, an exploratory factor analysis was done on the data from the survey to look for underlying common factors. Table II presents the simple correlations between the survey questions. Eigenvalues from principal components factor analysis along with the eigenvalues greater than one rule-of-thumb suggested keeping eight factors. The scree plot was inconclusive, suggesting either three, four or five factors. Research by Tucker, Koopman, and Lynn (1969) using Monte Carlo simulation suggests that the scree plot information yields consistently better results than the eigenvalues greater than one rule. Based on those research findings and on the inconclusive results of the scree plot on the number of factors to retain, three different principal axis factor analyses with Harris Kaiser rotations were done, retaining three, four, and five factors. These were then examined for interpretability to determine which solution should be retained, as suggested by Hakstian, Rogers, and Catell (1982). The five-factor solution provided the most meaningful interpretation (Table IV presents the rotated factor pattern). The five-factor solution accounted for 47.22 percent of the total variance. Table $V$ gives the proportion of common variance and the proportion of total variance explained by each factor. 
The variables that loaded on Factor one involved the amount of training members of the organization had received on ERTW programs, whether or not the organization paid its light duty employees their regular wage, whether or not the organization regularly contacted the medical care provider to discuss the prognossis, and whether or not the organization worked with the injured employee to help them return to work. After examining the make-up of all of the other factors, this factor was interpreted as the non-ERTW approach to dealing with injured workers. This approach appears to be more less positively proactive than the ERTW approach. Factor one is characterized by companies that train their employees in light duty programs, do not offer regular wage, call the medical provider, and work with the injured employee to get him/her back to work. Also important are the variables that do not load on this factor. Percent of cases in which light duty is used, written descriptions of physical load for various positions, level of dedication to ERTW, having the employee call the organization while off work, and telling current employees about their ERTW are all examples of variables with near zero loadings. These are all action components of an ERTW program, whereas the variables that do load on this factor are passive components which do not by themselves constitute an ERTW program.

Factor two characterizes organizations that have an ERTW program in which the employee's supervisor is involved 
In the decision-making process and who make the employees' supervisor responsible for assuring that the employee does not exceed the physical limitations prescribed by the physician. This factor was interpreted as organizations' perceptions of ERTW programs. When organizations say they have an ERTW program, they also frequently report involving supervisors in decision making and making them responsible for assuring that the injured employee does not exceed the physician's prescribed physical limitations. Other variables that had loadings above 0.35 on this factor were the amount of training people in the organization had received on ERTW, whether the organization used regular wage, and the extent to which the organization had written descriptions of the physical demands of each position. However, each of these variables loaded more highly on some other factor. This suggests that while these three variables play some role in organizations' perceptions of ERTW programs, these variables are more strongly associated with some other factor.

Organizations that score high on factor three did not prefer to wait until the employee was completely recovered before returning them to work, use light duty, and tend to use light duty in a high percentage of injury cases, require the injured employee to call them regularly while off work, and tend to have a high level of dedication to the ERTW program. (Level of dedication to the ERTW program was assessed by the survey respondent on a scale of 1 to 5 , 
where 5 indicated "extremely dedicated".) This factor was interpreted as the extent of implementation of the ERTW program. It accounted for more variance than any other factor.

Factor four is characterized by organizations who tell their new employees about the existence of their ERTW program, who make current employees aware of their program before they experience an on-the-job injury, who require their employees to sign a form stating that they agree to abide by the ERTW program, and who had positive relationships with the medical providers caring for their injured employees. This factor was interpreted as organizational communication regarding ERTW.

Factor five involved organizations with written policies for returning their injured employees to work, with written ERTW programs, and with detailed written descriptions of the physical demands of their positions. This factor was interpreted as the written formalization for dealing with injured workers, which can exist whether or not an organization has chosen an ERT'W approach.

Inter-factor correlations were high (see Table VI), ranging from 0.28 to 0.66 . This confirms that the decision to use a rotation that allows the factors to be highly correlated was appropriate. Further examination of the inter-factor correlations supports the interpretations of the factors. The strongest relationship between factors involves the organizations' perception of ERT'W programs 
(Factor 2) and the extent of ERTW program (Factor 3). There is also a strong relationship between communication of the ERTW program (Factor 4) and the extent of written formalization of programs (Factor 5). The relationships between the extent of ERTW program (Factor 3) and communication (Factor 4) and the extent of written formalization (Factor 5) are moderate, as would be expected (because the breakdown of the factors suggests that an organization can have an extensive ERTW program, but still have relatively low levels of communication and written formaliztion for it and because organizations who do not use the ERTW approach can still choose to have written formalization of their program). The relationship between non-ERTW approach (Factor 1) and the extent of program (Factor 3) is only moderate, suggesting that these two factors may represent alternative ways of dealing with injured employees, where Factor 1 is made up of those organizations who do not embrace the ERTW approach (who use ERTW rather superficially) and Factor 3 is made up of those organizations who do embrace the ERTW approach. The moderate relationship likely arises from those that are ambivalent about the approach and those who are in the process of moving from one paradigm to the other (based on information obtained during the survey process, it seems that an ERTW program is not something an organization either has or does not have, but instead is something that evolves over time). 


\section{CONFIRMATORY FACTOR ANALYSIS PROCESS/INDICES}

To further examine the underlying (latent) variables from the ERTW survey, additional work was done using confirmatory factor analysis. This process involves an examination of how well the hypothesized relationships between the latent and measured variables fit the data. To do this, the model is tested by examining the measures of fit. Then non-significant paths are deleted and significant paths not formerly in the model are added (within theoretical constraints).

There are two types of measures of fit which are used to examine how well the data fit the model in covariance structure modeling. The "overall" measures of fit give the researcher an idea of how well the entire model fits the data. They are described below, along with the commonly accepted level, although the acceptable levels can change somewhat from discipline to discipline (Bollen, 1989):

1) $x$ - a test of the null hypothesis that the model fits the data. It is desirable to minimize $x$ as part of the fitting process. However, because it is extremely sensitive to sample size, it is highly likely that this measure of fit will tell the researcher to reject the null hypothesis. One rough indicator can be obtained by dividing the chi-square statistic by the degrees of freedom. A ratio of three to one or less is desirable.

2) Goodness of Fit Index (GFI) - examines the 
difference between the predicted and observed data matrices. It varies between 0 and 1 , with fit improving as a value of 1 is approached. Values above .85 are acceptable fit of the data to the model. This indicator of fit cannot be compared from one model to another because it is affected by the degrees of freedom (which vary from one model to another).

3) Adjusted Goodness of Fit Index (AGFI) - The AGFI is adjusted for the degrees of freedom in the model. Again, it varies from 0 to 1 , where a higher number indicates better fit. Values above .80 are considered good fit of the model to the data. This indicator can be used to compare results across models.

4) Root Mean Square Residual (RMSR) - The RMSR is the average difference of the observed data matrix and the corresponding predicted matrix. It can easily be interpreted in terms of correlation matrices, where it is the average residual between the predicted and observed correlations. In this case, RMSR varies from 0 to 1 , and residuals of less than 0.10 are considered acceptable.

The second type of fit measures are detailed measures of fit which allow the researcher to examine the fit of a specific part of the model to the data. They are as follows:

1) Modification Indices - These indices describe how much the fit of the model would improved by adding a directional or correlational path in the model. The size is interpreted according to the size of the overall chi square 
statistic - if that path were added, the chi square would drop by the amount of the modification index).

2) t-values - One $t$-value is computed for each "free parameter" (or path) specified in the model. These test the null hypothesis that the free parameter is not significantly different from zero. T-values greater than two signify a significant path in the model.

\section{CONFIRMATORY FACTOR ANALYSIS WITHOUT STATE VARIABLES}

Since the initial goal of the study was to develop a structural model of ERTW components and their effectiveness, when the confirmatory factor analysis was conducted, two additional factors were created. The first five factors were those revealed in the exploratory factor analysis. However, survey respondents' responses to the question about whether the organization had an ERTW program was pulled from Factor two to create a sixth single-indicator Factor. It was believed that this variable should be predictive of the organizations' policies and practices relating to injured workers, rather than a component of the program. Regular wage was pulled from Factor one to create the seventh single-indicator Factor. It was expected that this financial variable may relate differently to the dollar outcome variables than the rest of Factor 1 .

The LISREL statistical package was used to do the confirmatory factor analysis. The analysis of the seven factor model (with just the data from the survey variables) 
confirmed on the hold-out sample. Measures of fit were as follows :

1) $\mathrm{X}(122)=245.55, \mathrm{p} \cdot=0.000$.

2) Goodness of Fit Index $=0.808$

3) Adjusted Goodness of Fit $=0.731$

4) Root Mean Square Residual $=0.166$

5) Maximum Modification Index $=32.89$

6) Several t-values were not significant.

The t-value for the loading of relationship with doctors on the communication factor was 1.882. This is not surprising, as data on this variable was available for only a few organizations. The $t$-value for the relationship between the light duty variable and the extent of implementation of ERTW factor was 1.386 and the $t$-value for the relationship between the variable which involved having the off-work employee call the company and the extent of implementation factor was 1.048. The measures of fit are just short of what is generally considered acceptable fit of the model to the data. Examination of the modification indices did not suggest any logical modifications for the model.

\section{CONFIRMATORY FACTOR ANALYSIS WITH STATE VARIABLES}

Using the initial sample, a second confirmatory factor analysis was conducted for a nine factor model. It included the seven previous factors plus two factors dealing with the outcome measures from the state data. A dollars factor with median medical costs and median wage reimbursememt costs as indicators was hypothesized for the first outcome. The 
second outcome factor was hypothesized as a people statistics factor with the variables relating to the number of reopened workers' compensation cases, the number of nondisabling claims, and the number of open cases, as indicators.

The fit indices for the nine-factor measurement model on the original sample were as follows:

1) $\mathrm{X}(227)=273.79(\mathrm{p}=0.018)$

2) Goodness of $\mathrm{fit}$ index $=0.833$

3) Adjusted goodness of fit index is 0.779

4) Root mean square residual is 0.081

The largest modification index was 9.69 and all $t$ values were significant. While the overall fit of the model is not quite as good as desired, the detailed measures of fit do not suggest any changes that could be made to substantially improve the fit of the model (that is, all variables are loading highly on their respective factors). These indices may be elevated because the first five factors were identified using this sample.

This nine-factor model was then confirmed on the holdout sample to examine stability. The results were as follows :

1) $\mathrm{X}(227)=333.7(\mathrm{p} .=0.000)$

2) Goodness of Fit Index $=0.804$

3) Adjusted Goodness of Fit Index $=0.740$

4) Root Mean Square Residual $=0.098$

5) The largest modification index was 22.78 .

6) All t-values were significant except that for

the relationship between the relationship with doctors variable and the communication factor. Again, this is not surprising because of the small amount of data available 
for this variable.

An attempt was also made to find a structural

model (which would identify the relationships between the constructs) to fit the data. However, because it did not work out well (quite possibly for reasons discussed later in the paper), those efforts are not detailed herein.

\section{MULTIPLE REGRESSION}

One of the major questions associated with ERTW programs is whether such programs actually reduce organizations' workers'compensation costs over time. To begin to answer this question, regression analysis was done on 176 organizations for which both 1985 and 1990 data was available. The goal of this analysis was to examine the extent to which the variation in organizations' programs and policies can predict:

1) A decrease in median medical costs per injury between 1985 and 1990 (when adjusted for inflation) and

2) A decrease in median wage reimbursement payments between 1985 and 1990 (when adjusted for inflation).

Therefore, the regression equations were designed to try to predict the following:

$1990 \$$ - 1985\$ + cumulative inflation adjustments. To estimate the inflation adjustment, the following sources were used: 
1) To estimate the rate of inflation in medical costs, the annual percent of change in total medical care services from the Consumer Price Index (1992) was used. Their data was taken from U.S. Bureau of Labor Statistics, 1991 and unpublished data. The resulting cumulative adjustment for the five year period between 1985 and 1990 was 43.28 percent.

2) To estimate the rate of inflation in wages two sources were used. For the years of 1985 to 1989, the U.S. Department of Labor, Bureau of Labor and Statistics (1991) was consulted. This source breaks down the percent change in average annual pay by state, so data for the state of Oregon was used. The resulting cumulative inflation for the four year period was 13.9 percent. Because this source did not yet have data available for 1990, another source had to be used to estimate the inflationary change in wages for that year. The U.S. Department of Commerce, Economics and Statistics Administration, Bureau of Economic Analysis (1991) was consulted. This source did not offer precisely equivalent data. What it did offer was a graph depicting the percent change in private sector wages for 1989-1990. The graph depicts approximately a 4.4 percent change for that time period. Combining this figure with that cited previously brings the total adjustment for wages for the five year period to 18.3 percent.

Descriptive statistics for the newly created variables were as follows: 
1) Change in median medical costs (adjusted for inflation) had a mean increase of $\$ 1,454.75$ and a standard deviation of $\$ 3,346.63$. The minimum adjusted change in median medical costs from 1985 to 1990 was a decrease of $\$ 11,196$ and the maximum was an increase of $\$ 25,578$.

2) Change in median wage reimbursement costs (adjusted for inflation) had a mean increase of $\$ 388.41$ and a standard deviation of $\$ 3,486.50$. The minimum change in the adjusted median medical costs from 1985 to 1990 was a decrease of $\$ 21,135$ and the maximum was an increase of $\$ 31,317$.

3) The correlation between these above two variables was $0.734(\mathrm{p} .=0.0001)$.

The simple correlations between the survey questions and the change in median medical costs and the change in median wage reimbursement costs are reported in Table VII. Only three variables were significantly related to change in median wage reimbursement costs over time. These correlations suggest that organizations with ERTW programs lowered their wage reimbursement costs, organizations that preferred to wait until the injured employee was fully recovered before returning him/her to work had higher wage reimbursement costs and that higher levels of dedication to ERT'W resulted in lower wage reimbursement costs.

Six variables were significantly related to change in the median medical costs of workers' compensation claims (see Table VII). These included the three variables that were significantly related to wage reimbursement costs - 
whether the organization had an ERTW program, whether the organization preferred to wait until the injured employee was fully recovered to return them to work, and the level of dedication to the ERTW program which were related to medical costs in the same manner they were related to wage reimbursement costs. In addition, increasing supervisory involvement in ERTW decision for their supervisees, making the injured employee's supervisor responsible for assuring that $s /$ he does not exceed the physicians prescribed limitations, and using an injured employees' regular wage when they are working in a light-duty position were all strategies which were associated with lower medical costs. (All three of these variables had negative correlations with the change in median medical costs).

The results of the regression to predict the change in workers' compensation medical costs revealed that all of the program variables together could significantly predict a substantial amount of the variance $-R=0.296, p=0.003$ and adjusted $R=0.172$. (See Table VIII for information on each variable). Three of the variables had regression coefficients which were significant, meaning that their unique contribution to predicting the outcome was significant. Those variables were whether or not the organization used regular wage for employees on light duty $(p .=0.008)$, extent to which the physical load of positions was written in detail $(p .=0.036)$ and the level of dedication the survey respondent perceived others in the 
organization to have to the light duty program ( $\mathrm{p} .=0.009)$. All three were related to a better change medical costs over time.

Also examined were the ability of the variables comprising each factor to predict the change in medical costs over time (adjusted for inflation). Seperate analyses (as opposed to hierarchical) were done, as the researcher was interested in the individual ability of each factor to account for the variance in change over time. Significant results were obtained for the following factors:

1) Extent of program $(R=0.089, \mathrm{p} .=0.018)$ in which the percent of cases in which light duty is used and the level of dedication to ERTW both had significant regression coefficients

2) Whether or not regular wage is offered $(\mathrm{R}=$ $0.033, \mathrm{p} .=0.027$ ) which has regular wage while on light duty as its single indicator

3) Organizations' perceptions of ERTW ( $R=0.047, \mathrm{p}$. $=0.026$ ) in which neither variable (level of supervisor's involvement in decision-making and making someone responsible for assuring that the injured employee does not exceed the doctor's prescribed physical limitations) was in itself significant, but the overall factor is. Apparently, neither variable contributes enough unique ability to predict change significantly, but their joint effect was. See Table IX for detailed results of these regression analyses. 
The results of the regression to try to predict change in workers' compensation wage reimbursement costs revealed that all of the program variables together could significantly predict a portion of the variance in that variable $-R=0.243, \mathrm{p} .=032$ and adjusted $R=-$ 0.110. See Table $X$ for information on 39 each of the variables. The variables that contributed significantly to the model were wether or not the organization had a written return-to-work policy $(\mathrm{p} .=049)$ and whether or not regular wage was given to employees on light duty $(p .=0.003)$. Having a written policy and using regular wage were both related to better performance on change in wage reimbursement costs over time. None of the factors could significantly predict the change in wage reimbursement costs from 1985 to 1990. The only variable that had a t-value of significance involved the extent to which the organization had written descriptions of the physical load demands in their various positions.

A COMPARISON OF HIGH VERSUS LOW PERFORMING ORGANIZATIONS (IN TERMS OF WORKERS' COMPENSATION COSTS)

To further examine those features of return-to-work programs and policies that affect workers' compensation costs, the organizations that fell into the top and bottom quartiles for medical costs and for wage reimbursement costs were separated out for comparison of the features of their 
programs.

The range of the 41 organizations with the worst performance on the change in median wage reimbursement costs (median 1990 wage reimbursement costs - median 1985 wage reimbursement costs + cumulative inflation adjustment) was from an increase of $\$ 25,567.67$ to $\$ 1,627.97$. Of the 41 organizations with the best performance on the change in median wage reimbursement costs, the range was from an increase of $\$ 330$ to a decrease of $\$ 11,195.60$. Based on the binomial test (which examines a single groups' tendency to do one thing over another, not the differences between the best and worst performing groups) at the 0.05 level of significance, a comparison of the components of ERTW programs for the firms in the upper quartile and the same comparison for firms in the lower quartiles revealed some interesting differences between them (see Table XII):

1) While both the best and worst performing organizations were significantly more likely to report that they had an ERTW program than they were to report that they did not have such a program, organizations with the best performance records on the change in median wage reimbursement costs were also significantly more likely to report that they used light duty in 75-1008 of the eligible cases of injury and that their organization was "extremely dedicated" to the use of ERTw. No trend was found for the worst performers.

2) Poor performers on the change in median wage 
reimbursement costs were significantly less likely to have a written ERTW program than they were to not have a written program. They were also somewhat less likely to tell new employees about their ERTW program (significant at the 0.10 level of probability). The best performers did not show significant trends in any direction on either of these variables.

3) Both the best and the worst performers had significant tendencies to usually or always involve the injured employee's supervisor in decisionmaking about ERTW and to have someone (almost always the supervisor) be responsible for making sure that the injured employee did not exceed his/her doctor's prescribed physical limitations.

4) Organizations with the best performance on the change in median wage reimbursement costs were significantly more likely to use the employees regular wage for light/modified duty than to use some other (lower) wage. Organizations with the worst performance did not exhibit a significant trend in either direction. In addition, there were a number of variables on which there were significant trends in the same direction for both the best and the worst performing organizations. This includes the following: both types of organizations were more likely to report having an ERTW program than they were to report not having one and to prefer to bring the injured employee back before they are fully recovered, both types of organizations were more likely to involve the supervisors than to not involve 
them, and both types were likely to make the supervisors responsible for assuring that the injured employee on light duty followed the doctor's prescribed physical limitations. Both the best and worst performing organizations were more likely to have the employee call them while out on injury than to not require such communication, were more likely to call the doctors than to not call them, and were more likely to work with the injured worker than to not work with them. None of the chi-square tests for differences between the best and worst performing organizations were significant at the 0.01 level (none even made significance at the 0.05 level). This finding is consistent with the failure of any of the regressions to be able to predict this variable. It is not surprising that the chi-square tests are not significant. It is not necessarily expected that the best and worst performers do opposite things. It may be that the best performers are consistent while the worst performers are variable or that the best performers are flexible while the worst performers are more rigid.

of the 41 organizations with the worst performance on the change in median medical costs (median 1990 medical costs - median 1985 medical costs + cumulative inflation adjustment), the scores ranged from an increase of $\$ 31,317.32$ to $\$ 789.70$. Of the 41 organizations with the best performance on the change in median medical costs, the scores ranged from an increase of $\$ 161.56$ to a decrease of $\$ 12,1135.50$. Based on the binomial test at the 0.05 level 
of significance (again, this test examines a single groups tendency to choose one approach over another, not the difference between the best and worst performing organizations' approaches), a comparison of the components of ERTW programs for the firms in the upper and the same comparison for the firms in the lower quartiles revealed some interesting differences between them (see Table XIII):

1) While both the best and worst performing organizations were significantly more likely to report that they had an ERTW program than they were to report that they did not have such a program, organizations with the best performance records on the change in median wage reimbursement costs were also significantly more likely to report that they used light duty in 508 or more of the eligible cases of injury while those organizations in the worst performing group did not show this trend. The best performing organizations were also significantly more likely to report that their organizations had a dedication level to ERTW of 4 or 5 (where 5 = "extremely dedicated), whereas the worst performing organizations showed this tendency only at the 0.10 level of significance.

2) Poor performers on the change in median medical costs variable were somewhat more likely to not tell new employees about their ERTW programs (significant at the 0.10 level of probability) than they were to tell them. Good performers did not have a significant trend in either direction on this variable. 
3) Both the best and the worst performers had significant tendencies to usually or always involve the injured employee's supervisory in decision-making about ERTW and to have someone (almost always the supervisor) be responsible for making sure that the injured employee did not exceed his/her doctor's prescribed physical limitations.

4) Organizations with the best performance on the change in median wage reimbursement costs were significantly more likely to use the employees regular wage for light/modified duty than to use some other (lower) wage. Organizations with the worst performance did not exhibit a significant trend in either direction. Again, there were a number of variables for which both the best and worst performing organizations had significant trends in the same direction. As with the best and worst performers on the wage reimbursement variable, like trends included being more likely to have an ERTW program than to not have one, a preference for bringing injured employees back to work before they are fully recovered, a preference for involving supervisors in decision making, and for making supervisors responsible for assuring that the injured employee does not exceed the doctors' prescribed physical limitations. As is the case with the wage reimbusement variable, like trends were also shown for asking the injured employee to call the organization while off work, working with the injured worker more often than not, preferring to call the doctors, and preferring to work with the injured worker. None of the 
chi-square tests for differences between the best and worst performing organizations were significant at the 0.01 level. Only organizations' reports of their relationships with doctors was significant at the 0.05 level, with the best performing organizations reporting both more incidences of good and bad relationships with doctors. This suggests that the best performing organizations are more aware of their relationships with the medical community and of the importance of those relationships.

Interestingly, while there were 41 organizations in each quartile, only 19 of those were in the best-performing quartile for change in median medical costs and median wage reimbursement costs and only 21 were in the bottom quartile for change in median medical costs and median wage reimbursement costs. This finding suggests that there may be separate steps that can be taken to improve organizational performance on these two cost factors for workers' compensation, although the comparison findings discussed previously did not show great differences between the change in wage reimbursement costs and the change in medical costs. 
TABLE I

DESCRIPTIVE STATISTICS FOR THE SURVEY QUESTIONS

Variable Response Frequency Percentage

Written Policy

$\begin{array}{lll}\text { Yes } & 99 & 57.6 \\ \text { No } & 73 & 42.4\end{array}$

ERTW

$\begin{array}{lll}\text { Yes } & 82 & 48.0 \\ \text { No } & 89 & 52.0\end{array}$

Tell New Empl.

$\begin{array}{lll}\text { Yes } & 62 & 36.7 \\ \text { No } & 107 & 63.3\end{array}$

Tell Current E.

$\begin{array}{rll}\text { All } & 51 & 29.8 \\ \text { Most } & 23 & 13.5 \\ \text { Some } & 26 & 15.2 \\ \text { After Injury } & 50 & 29.2 \\ \text { No } & 21 & 12.3\end{array}$

Sign Form

$\begin{array}{lrr}\text { Yes } & 25 & 14.7 \\ \text { No } & 145 & 85.3\end{array}$

Supervisor Involved

$\begin{array}{rrr}\text { Always } & 97 & 57.7 \\ \text { Usually } & 23 & 13.7 \\ \text { Sometimes } & 15 & 8.9 \\ \text { Never } & 33 & 19.6\end{array}$

Not Exceed

$\begin{array}{lrr}\text { Yes } & 138 & 81.2 \\ \text { No } & 32 & 18.8\end{array}$

Training

$\begin{array}{lll}\text { Extensive } & 40 & 24.4 \\ \text { Moderate } & 60 & 36.6 \\ \text { A Little } & 15 & 9.1 \\ \quad \text { None } & 49 & 29.2\end{array}$

Relations w/ Doctors

Contributes

to Success

Not Commented on

Hinders Success 
TABLE I

DESCRIPTIVE STATISTICS FOR THE SURVEY QUESTIONS

(Continued)

Variable Response Frequency Percentage

Prefer to wait

$\begin{array}{rrr}\text { Yes } & 19 & 11.1 \\ \text { In Some Cases } & 12 & 7.0 \\ \text { No } & 140 & 81.9\end{array}$

Light Duty

$\begin{array}{lrr}\text { Yes } & 160 & 93.6 \\ \text { No } & 11 & 6.4\end{array}$

Percent Light Duty

$\begin{array}{rrr}08 & 11 & 6.7 \\ \text { Under } 258 & 23 & 14.0 \\ 258 \text { to } 498 & 4 & 2.4 \\ 508 \text { to } 758 & 17 & 10.4 \\ 768 \text { to } 1008 & 109 & 66.5\end{array}$

Regular Wage

$\begin{array}{lrr}\text { Yes } & 136 & 86.6 \\ \text { No } & 21 & 13.4\end{array}$

Empl. Call Company

$\begin{array}{lrr}\text { Yes } & 123 & 72.4 \\ \text { No } & 47 & 27.6\end{array}$

Company Call Dr.

Yes

No

123

47

72.4

27.6

Work w/ Worker

$\begin{array}{lrr}\text { Yes } & 146 & 85.9 \\ \text { No } & 24 & 14.1\end{array}$

Physical Load

$\begin{array}{lrr}\text { None } & 51 & 29.8 \\ \text { Some } & 32 & 18.7 \\ \text { Most } & 9 & 5.3 \\ \text { All } & 79 & 46.2\end{array}$


TABLE I

DESCRIPTIVE STATISTICS FOR THE SURVEY QUESTIONS (Continued)

Variable Response Frequency Percentage

Dedication

$\begin{array}{rrr}0 & 14 & 8.2 \\ 1 & 2 & 1.2 \\ 2 & 3 & 1.8 \\ 3 & 16 & 9.4 \\ 4 & 29 & 17.0 \\ 5 & 107 & 62.6\end{array}$

(where 5 = extremely dedicated) 
TABLE II

SIMPLE CORRELATIONS BETWEEN SURVEY QUESTIONS

\begin{tabular}{|c|c|c|c|}
\hline & ERTW & Writprog & Tellnew \\
\hline Written Policy & $0.255 *$ & 0.487 * & $0.408 *$ \\
\hline ERTW & 1.000 & 0.359 * & 0.287 * \\
\hline Written Program & $0.359 *$ & 1.000 & $0.252 *$ \\
\hline Tell New Empl. & 0.287 * & $0.252 *$ & 1.000 \\
\hline Tell Current E. & 0.570 * & 0.327 * & $0.450 *$ \\
\hline Sign Form & 0.156 * & 0.269 * & $0.345 *$ \\
\hline Super. Involve. & $0.659 *$ & 0.281 * & 0.267 * \\
\hline Not Exceed & $0.780 *$ & $0.375 *$ & $0.340 *$ \\
\hline Training & $0.516 *$ & 0.371 * & $0.416 *$ \\
\hline Doctor Relation. & 0.054 & 0.027 & $0.190 *$ \\
\hline Prefer to Wait & $-0.567 *$ & $-0.289 *$ & $-0.214 *$ \\
\hline Lt. Duty & 0.468 * & 0.113 & 0.090 \\
\hline Percent Lt. Duty & $0.705 *$ & 0.239 & $0.197 *$ \\
\hline Regular Wage & 0.064 & -0.084 & -0.037 \\
\hline Emp. Call Company & 0.208 * & $0.301 *$ & 0.076 \\
\hline Company Call Dr. & 0.020 & $0.199 *$ & 0.091 \\
\hline Work w/ Worker & 0.304 * & 0.127 & $0.217^{\star}$ \\
\hline Physical Load & 0.108 & $0.243 *$ & 0.192 * \\
\hline Dedication & 0.784 * & $0.345 *$ & 0.223 * \\
\hline
\end{tabular}

Tellcurr Signform Super Involved

\begin{tabular}{|c|c|c|c|}
\hline & & & \\
\hline Written & $0.410 *$ & $0.255 *$ & 0.227 \\
\hline ERTW & 0.570 * & $0.156 *$ & 0.659 \\
\hline Written Program & 0.327 * & $0.269 *$ & $0.281 *$ \\
\hline Tell New Empl. & $0.450 *$ & 0.345 & 0.267 \\
\hline Tell Current E. & 1.000 & 0.352 * & 0.293 \\
\hline Sign Form & 0.352 * & 1.000 & 0.080 \\
\hline Super. Involve. & $0.293 *$ & 0.080 & 1.000 \\
\hline Not Exceed & $0.398 *$ & $0.159 *$ & 0.593 \\
\hline Training & $0.446 *$ & $0.200 *$ & 441 \\
\hline Doctor Relation. & 0.194 * & 0.008 & 0.076 \\
\hline Prefer to Wait & $-0.323 *$ & -0.111 & -0.381 \\
\hline Lt. Duty & 0.226 * & 0.101 & 0.334 \\
\hline Percent Lt. Duty & 0.454 * & $0.153 *$ & 0.419 \\
\hline Regular Wage & 0.021 & -0.039 & 0.105 \\
\hline Emp. Call Company & 0.150 * & 0.069 & 0.057 \\
\hline Company Call Dr. & 0.107 & 0.066 & 0.073 \\
\hline Work w/ Worker & $0.186 *$ & 0.045 & 0.215 \\
\hline Physical Load & $0.158 *$ & 0.105 & \\
\hline Dedication & 0.499 * & 0.117 & 0 . \\
\hline
\end{tabular}


TABLE II

SIMPLE CORRELATIONS BETWEEN SURVEY QUESTIONS (Continued)

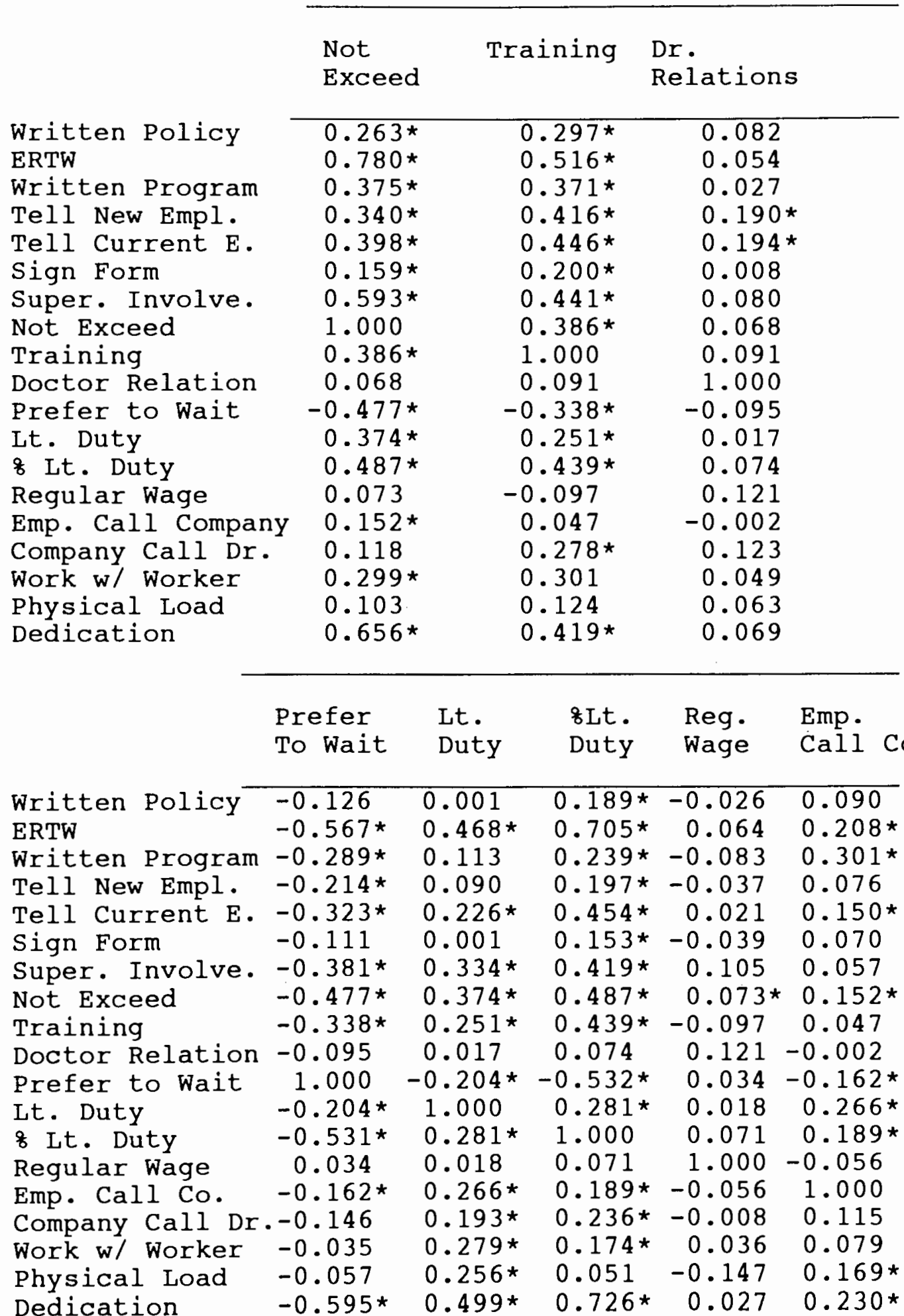


TABLE II

SIMPLE CORRELATIONS BETWEEN SURVEY QUESTIONS (Continued)

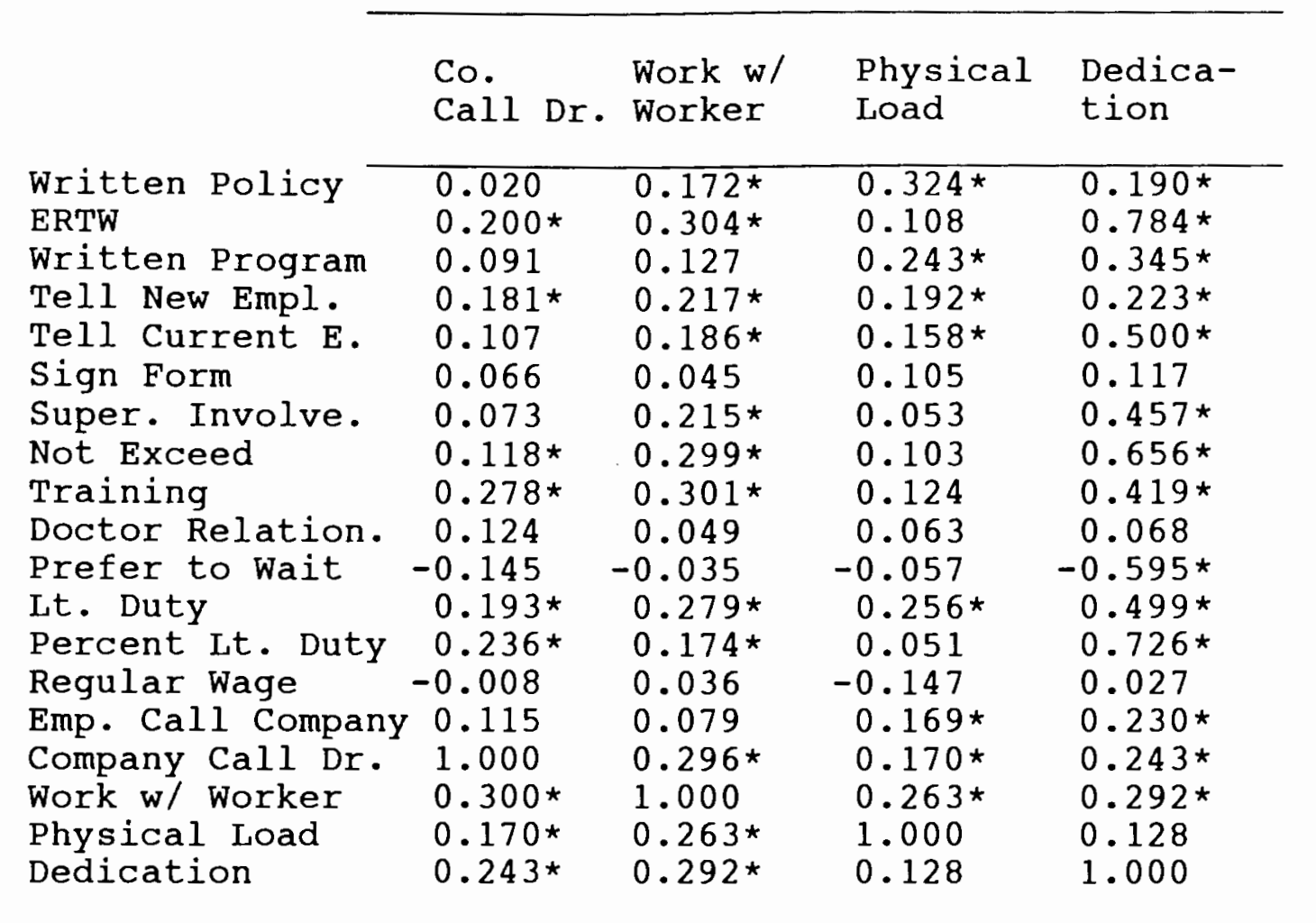

Note: * $-r$ is significant at the 0.05 level. ** - organizations w/o ERTW were not asked about their level of dedication to ERTW program. 
SIMPLE CORRELATIONS BETWEEN THE SURVEY QUESTIONS AND THE ORGANIZATIONAL OUTCOME VARIABLES

\begin{tabular}{|c|c|c|c|}
\hline $\begin{array}{l}\text { Survey } \\
\text { Question }\end{array}$ & $\begin{array}{l}\text { Open } \\
\text { Claims }\end{array}$ & $\begin{array}{l}\text { Non-Disabling } \\
\text { Claims }\end{array}$ & $\begin{array}{l}\text { Reopen } \\
\text { Claims }\end{array}$ \\
\hline $\begin{array}{l}\text { Written Policy } \\
\text { ERTw } \\
\text { Written Program } \\
\text { Tell New Empl. } \\
\text { Tell Current E. } \\
\text { Sign Form } \\
\text { Super. Involve. } \\
\text { Not Exceed } \\
\text { Training } \\
\text { Dr. Relations } \\
\text { Prefer to Wait } \\
\text { It. Duty } \\
\text { \& Lt. Duty } \\
\text { Regular Wage } \\
\text { Call Company } \\
\text { Company Call } \\
\text { Work w/ Worker } \\
\text { Physical Load } \\
\text { Dedication }\end{array}$ & $\begin{array}{l}0.179 \star \\
0.091 \\
0.115 \\
0.152 \star \\
0.042 \\
-0.092 \\
0.097 \\
0.105 \\
0.165 \star \\
0.054 \\
-0.086 \\
0.050 \\
0.136 \\
-0.095 \\
-0.076 \\
0.097 \\
0.108 \\
0.138 \\
0.113\end{array}$ & $\begin{array}{l}0.205^{\star} \\
0.117 \\
0.101 \\
0.104 \\
0.046 \\
-0.080 \\
0.062 \\
0.100 \\
0.177 \star \\
0.033 \\
-0.121 \\
0.052 \\
0.179 \star \\
-0.059 \\
-0.067 \\
0.131 \\
0.084 \\
0.139 \\
0.148 \star\end{array}$ & $\begin{array}{l}0.118 \\
0.098 \\
0.151 \star \\
0.121 \\
-0.065 \\
-0.104 \\
0.052 \\
0.077 \\
0.191^{\star} \\
0.022 \\
-0.129 \\
0.083 \\
0.087 \\
-0.178 \star \\
0.006 \\
0.085 \\
0.112 \\
0.072 \\
0.056\end{array}$ \\
\hline
\end{tabular}

Note: * $-r$ is significant at the 0.05 level. 
TABLE IV

ROTATED FACTOR PATTERN FOR FIVE-FACTOR SOLUTION

\begin{tabular}{|c|c|c|c|c|}
\hline Variable & $\begin{array}{l}\text { Non-ERTW } \\
\text { Approach }\end{array}$ & $\begin{array}{c}\text { Orgs' } \\
\text { Perception } \\
\text { of ERTW }\end{array}$ & $\begin{array}{l}\text { Extent } \\
\text { of Imple- } \\
\text { mentation }\end{array}$ & $\begin{array}{l}\text { Com- } \\
\text { munica- } \\
\text { tion }\end{array}$ \\
\hline $\begin{array}{l}\text { Written Policy } \\
\text { ERTw } \\
\text { Written Program } \\
\text { Tell New Empl. } \\
\text { Tell Current E. } \\
\text { Sign Form } \\
\text { Super. Involve. } \\
\text { Not Exceed } \\
\text { Training } \\
\text { Doctor Relation. } \\
\text { Prefer to Wait } \\
\text { Lt. Duty } \\
\text { Percent Lt. Duty } \\
\text { Regular Wage } \\
\text { Emp. Call Company } \\
\text { Company Call Dr. } \\
\text { Work w/ Worker } \\
\text { Physical Load } \\
\text { Dedication }\end{array}$ & $\begin{array}{l}-0.131 \\
-0.080 \\
0.133 \\
0.088 \\
-0.004 \\
-0.082 \\
0.156 \\
-0.157 \\
0.539 \star \\
0.023 \\
-0.032 \\
0.105 \\
0.017 \\
-0.393 \star \\
-0.029 \\
0.579 \star \\
0.419 \star \\
0.048 \\
-0.048\end{array}$ & $\begin{array}{r}0.138 \\
0.644 \star \\
-0.022 \\
0.045 \\
0.055 \\
-0.281 \\
0.867 \star \\
0.674 \star \\
0.363 \\
-0.143 \\
-0.122 \\
-0.145 \\
0.183 \\
0.358 \\
-0.247 \\
-0.164 \\
0.197 \\
0.403 \\
0.055\end{array}$ & $\begin{array}{l}-0.163 \\
0.347 \\
0.067 \\
-0.084 \\
0.204 \\
0.100 \\
-0.131 \\
0.220 \\
-0.215 \\
0.033 \\
-0.571^{\star} \\
0.781^{\star} \\
0.684 \star \\
-0.040 \\
0.494 \star \\
0.205 \\
-0.033 \\
0.216 \\
0.927 \star\end{array}$ & $\begin{array}{r}0.095 \\
0.072 \\
-0.123 \\
0.768 \star \\
0.485^{\star} \\
0.498 \star \\
-0.100 \\
0.046 \\
0.092 \\
0.474 \star \\
-0.041 \\
-0.089 \\
-0.057 \\
0.195 \\
-0.226 \\
0.119 \\
-0.037 \\
0.009 \\
0.078\end{array}$ \\
\hline
\end{tabular}

NOTE: * - These variables were considered to load on that factor for the purposes of interpretation. 
TABLE IV

ROTATED FACTOR PATTERN FOR FIVE-FACTOR SOLUTION (Continued)

\begin{tabular}{lc} 
Variables & $\begin{array}{c}\text { Extent of } \\
\text { Communica- } \\
\text { tion }\end{array}$ \\
\hline Written Policy & $0.749 *$ \\
ERTw & 0.053 \\
Written Program & $0.685 *$ \\
Tell New Employ. & -0.053 \\
Tell Current E. & 0.199 \\
Sign Form & 0.260 \\
Super. Involve. & 0.054 \\
Not Exceed & 0.045 \\
Training & 0.257 \\
Doctor Relation. & -0.191 \\
Prefer to Wait & -0.041 \\
Lt. Duty & -0.094 \\
Percent Lt. Duty & 0.039 \\
Regular Wage & -0.236 \\
Call Company & 0.174 \\
Company Call & -0.257 \\
Work w/ Worker & -0.125 \\
Physical Load & $0.414 *$ \\
Dedication & -0.073 \\
& \\
\hline &
\end{tabular}

NOTE: * - These variables were considered to load on that factor for the purposes of interpretation, with the exception of ERTW, which was made into its own factor. 


\section{TABLE V}

STATISTICS FOR ROTATED FACTOR PATTERN FOR

FIVE-FACTOR SOLUTION

F1

F2

E3

F4

F5

Eigenvalues 5.601

1.516

0.946

0.733

0.639

Variance Accounted for:

Common
0.241
0.464
0.491
0.310
0.324

(variance explained by each ignoring others/final communality estimate)

Total
0.114

0.219

0.232

0.146

0.153

(variance explained by each ignoring other/\# variables) 
TABLE VI

INTER-FACTOR CORRELATIONS FOR THE ROTATED SOLUTION

\begin{tabular}{llllll}
\hline & F1 & F2 & F3 & F4 & F5 \\
F1 & 1.00 & & & & \\
F2 & 0.35 & 1.00 & & & \\
F3 & 0.46 & 0.67 & 1.00 & & \\
F4 & 0.35 & 0.43 & 0.37 & 1.00 & \\
F5 & 0.28 & 0.45 & 0.39 & 0.55 & 1.00 \\
\hline
\end{tabular}


SIMPLE CORRELATIONS BETWEEN THE SURVEY QUESTIONS AND THE CHANGE IN MEDICAL COSTS AND THE CHANGE IN WAGE REIMBURSEMENT COSTS

Survey

Questions
Change in

Medical \$
Change in wage

Reimbursement $\$$

$\begin{array}{llc}\text { Written Policy } & -0.042 & -0.010 \\ \text { ERTW } & -0.225^{\star} & -0.209 * \\ \text { Written Program } & -0.010 & -0.069 \\ \text { Tell New Empl. } & -0.055 & -0.071 \\ \text { Tell Current E. } & -0.042 & -0.095 \\ \text { Sign Form } & -0.043 & -0.025 \\ \text { Super. Involved } & -0.175 * & -0.135 \\ \text { Not Exceed } & -0.206^{\star} & -0.148 \\ \text { Training } & -0.096 & -0.096 \\ \text { Doctor Relation. } & -0.026 & -0.013 \\ \text { Prefer to Wait } & 0.249 * & 0.189 \\ \text { Lt. Duty } & -0.002 & -0.005 \\ \text { Percent Lt. Duty } & -0.030 & -0.003 \\ \text { Regular Wage } & -0.181 * & -0.138 \\ \text { Call Company } & 0.016 & 0.041 \\ \text { Company Call } & 0.053 & 0.015 \\ \text { Work w/ Worker } & 0.014 & 0.025 \\ \text { Physical Load } & 0.143 & 0.096 \\ \text { Dedication } & -0.252^{\star} & -0.221 \text { * }\end{array}$

Note: * $-r$ is significant at the 0.05 level. 
RESULTS OF REGRESSION TO PREDICT CHANGE IN MEDICAL COSTS FROM 1985 TO 1990, USING ALL PROGRAM COMPONENTS

$\begin{array}{lll}\text { Variable } & \begin{array}{l}\text { Parameter } \\ \text { Estimate }\end{array} \text { T-value Prob. }>|\mathrm{T}|\end{array}$

\begin{tabular}{lrrr}
\hline & & & \\
Intercept & 4224.46 & 2.647 & 0.009 \\
Writ. Pol. & 57.74 & -0.089 & 0.929 \\
Program Writ. & -224.19 & -0.350 & 0.727 \\
Tell New Emp. & -79.86 & -0.134 & 0.894 \\
Tell Current E. 131.58 & 0.587 & 0.558 \\
Sign Form & -673.79 & -0.923 & 0.358 \\
Supervis. Inv. -320.17 & -1.177 & 0.242 \\
Not Exceed Phys -253.00 & -0.277 & 0.782 \\
Training & 160.83 & 0.566 & 0.573 \\
Rel. w/ Doctors & 127.55 & -0.166 & 0.868 \\
Prefer to Wait & 986.47 & 1.915 & 0.058 \\
Light Duty & -159.08 & -0.169 & 0.866 \\
\& Lt. Duty & 398.64 & 1.295 & 0.198 \\
Regular Wage & -2099.54 & -2.723 & $0.008 *$ \\
Call Company & 551.50 & 0.896 & 0.387 \\
Company Call & 86.32 & 0.117 & 0.907 \\
Work w/ Worker & 1187.78 & 1.504 & 0.136 \\
Physical Load & 471.55 & 2.120 & $0.036 *$ \\
Dedication & -952.80 & -2.661 & $0.009 *$ \\
& & & \\
\hline
\end{tabular}

Notes: $\mathrm{R}=0.296$, Adj. $\mathrm{R}=0.172$. $\mathrm{F}(18,102)=$ $2.387, \mathrm{p} .=0.003 . *$ - Parameter estimate is significant at the 0.05 level. 
TABLE IX

RESULTS OF REGRESSION TO PREDICT CHANGE IN MEDICAL COSTS FROM 1985 TO 1990, USING THE VARIABLES

THAT MAKE UP EACH FACTOR

Factor $\begin{array}{ll}\text { Parameter } \\ \text { Estimate }\end{array}$ T-value Prob. $>|\mathrm{T}|$

Factor - Extent of Program

$\begin{array}{lrrl}\text { Intercept } & 1276.01 & 1.271 & 0.206 \\ \text { Prefer to wait } & 731.99 & 1.624 & 0.106 \\ \text { Light Duty } & 1148.65 & 1.450 & 0.149 \\ \text { 8 Light Duty } & 647.44 & 2.434 & 0.016 * \\ \text { Dedication } & -799.23 & -2.728 & 0.007^{*} \\ \text { Call Company } & 116.95 & 0.209 & 0.835 \\ & & & \\ \mathrm{R} \quad=0.089, \text { Adj. } \mathrm{R}=0.057 . & \mathrm{F}(5,145)=2.828, \\ \mathrm{P} . \quad=0.018 .\end{array}$

Factor - Regular Wage

$\begin{array}{lccl}\text { Intercept } & 3011.01 & 4.235 & 0.001 \\ \text { Regular Wage } & -1710.29 & -2.230 & 0.027 \\ & \\ \mathrm{R}=0.033, \text { Adj. } \mathrm{R}=0.026 . & \mathrm{F}(1,147)=4.971, \\ \mathrm{p} .=0.027\end{array}$

Factor - Organizations' Perceptions of ERTW

$\begin{array}{lrll}\text { Intercept } & 2950.67 & 4.811 & 0.001 \\ \text { Super. Inv. } & -228.41 & -0.864 & 0.389 \\ \text { Not Exceed } & -1331.30 & -1.652 & 0.101 \\ & & & \\ \mathrm{R}=0.047, \text { Adj. } \mathrm{R}=0.035 . & \mathrm{F}(2,155)=3.857, \\ \mathrm{p} .=0.026 . & & & \end{array}$


TABLE IX

RESULTS OF REGRESSION TO PREDICT CHANGE IN MEDICAL COSTS FROM 1985 TO 1990, USING THE VARIABLES THAT MAKE UP EACH FAC'TOR (Continued)

\begin{tabular}{lll} 
Factor & $\begin{array}{l}\text { Parameter } \\
\text { Estimate }\end{array}$ T-value & Prob. $>|T|$ \\
\hline
\end{tabular}

Factor - Extent of Written Program

\begin{tabular}{lrrr}
\hline Intercept & 1087.71 & 2.268 & 0.025 \\
Written Pol. & -162.26 & -0.258 & 0.797 \\
Written Prog. & -867.12 & -1.430 & 0.155 \\
Physical Load & 469.88 & 2.311 & 0.221 \\
R $=0.043$, Adj. $\mathrm{R}=0.024$. & $\mathrm{F}(3,156)=2.320$, \\
$\mathrm{p} .=0.078$.
\end{tabular}

Factor - Communication

$\begin{array}{lrrr}\text { Intercept } & 1662.78 & 3.308 & 0.001 \\ \text { Tell Curr. Emp. }-47.74 & -0.218 & 0.828 \\ \text { Sign Form } & -210.96 & -0.246 & 0.806 \\ \text { Relation. w/Docs }-127.30 & -0.135 & 0.893 \\ \text { Tell New Emp. }-380.03 & -0.584 & 0.560 \\ \mathrm{R}=0.006, \text { Adj. } \mathrm{R}=-0.021 . & \mathrm{F}(4,148)=0.236, \\ \mathrm{p}=0.918 .\end{array}$

Factor - Non-ERTW Approach

$\begin{array}{lccl}\text { Intercept } & 1224.57 & 1.579 & 0.1166 \\ \text { Training } & -372.57 & -0.1434 & 0.154 \\ \text { Company Call } & 636.57 & 0.877 & 0.382 \\ \text { Work w/ Worker } & 397.70 & 0.512 & 0.609 \\ \mathrm{R}=0.017, \text { Adj. } \mathrm{R}=-0.003 . & \mathrm{F}(3,148)=0.853, \\ \mathrm{p} .=0.467 .\end{array}$


TABLE $X$

RESULTS OF REGRESSION TO PREDICT CHANGE IN WAGE REIMBURSEMENT COSTS FROM 1985 TO 1990, USING ALL PROGRAM COMPONENTS

\begin{tabular}{lrll}
\hline & & & \\
Variable & Parameter & T-value & Prob. $|\mathrm{T}|$ \\
& & & \\
Intercept & 2456.65 & 2.176 & 0.032 \\
Written Pol. & 915.29 & 1.996 & $0.049 *$ \\
Written Prog. & -158.29 & -0.349 & 0.728 \\
Tell New Empl. -209.42 & -0.495 & 0.622 \\
Tell Current E. -72.96 & -0.460 & 0.646 \\
Sign Form & -384.41 & -0.744 & 0.459 \\
Super. Involve. -105.13 & -0.546 & 0.586 \\
Not Exced Phys 196.79 & $0.3-5$ & 0.761 \\
Training & 156.05 & 0.776 & 0.440 \\
Rel. w/ Doctors & 43.50 & 0.080 & 0.936 \\
Prefer to Wait -117.97 & -0.324 & 0.746 \\
Light Duty & -179.65 & -0.270 & 0.788 \\
\& Light Duty & -114.84 & -0.568 & 0.599 \\
Regular Wage -1693.75 & -3.105 & $0.003 *$ \\
Call Company & 404.06 & 0.900 & 0.370 \\
Company Call & 202.74 & 0.388 & 0.699 \\
Work w/ Worker & 537.07 & 0.961 & 0.339 \\
Physical Load & 243.67 & 1.549 & 0.125 \\
Dedication & -418.88 & -1.654 & 0.101 \\
& & & \\
\hline
\end{tabular}

Notes: $\mathrm{R}=0.243$, Adj. $\mathrm{R}=0.110 . \mathrm{F}(18,102)=$ $1.820 . \mathrm{p} .=0.032 . *$ - Parameter estimate is significant at 0.05 level. 


\section{TABLE XI}

RESULTS OF REGRESSION TO PREDICT CHANGE IN WAGE

REIMBURSEMENT COSTS FROM 1985 TO 1990, USING

THE VARIABLES THAT MAKE UP EACH FACTOR

Factor

Parameter

T-value Prob. $>|\mathrm{T}|$

Estimate

Factor - Regular Wage

$\begin{array}{lccc}\text { Intercept } & 1591.78 & 2.334 & 0.021 \\ \text { Regular Wage } & -1245.83 & -1.693 & 0.093 \\ & \\ \mathrm{R}=0.019, \text { Adj. } \mathrm{R}=0.013 . & \mathrm{F}(1,147)=2.867, \\ \mathrm{p} .=0.093 . & \end{array}$

Factor - Extent of Program

$\begin{array}{lrcl}\text { Intercept } & 388.14 & 0.435 & 0.664 \\ \text { Prefer to wait } & 198.54 & 0.496 & 0.621 \\ \text { Light Duty } & 540.45 & 0.767 & 0.444 \\ \text { \& Light Duty } & 370.79 & 1.568 & 0.119 \\ \text { Call Company } & 174.30 & 0.350 & 0.727 \\ \text { Dedication } & -495.67 & -1.903 & 0.059 \\ & & & \\ \mathrm{R}=0.033, \text { Adj. } \mathrm{R}=0.001 . & \mathrm{F}(5,145)=0.994, \\ \mathrm{P} .=0.424 .\end{array}$

Factor - Organizations' Perceptions of ERTW
Intercept
1576.11
2.404
0.017
Super. Involve. -217.32
$-0.769$
0.443
Not Exceed
$-933.09$
$-1.083$
0.281
$R=0.026, \operatorname{Adj} \cdot R=0.013 . F(2,155)=2.052$,
$\mathrm{p} .=0.132$. 


\section{TABLE XI}

RESULTS OF REGRESSION TO PREDICT CHANGE IN WAGE REIMBURSEMENT COSTS FROM 1985 TO 1990, USING THE VARIABLES THAT MAKE UP EACH FACTOR (Continued)

Factor

Parameter

Estimate

T-value Prob. $>|\mathrm{T}|$

Factor - Extent of Written Program

$\begin{array}{lrrr}\text { Intercept } & 167.29 & 0.326 & 0.745 \\ \text { Written Pol. } & 18.48 & 0.027 & 0.978 \\ \text { Written Prog. } & -694.97 & -1.069 & 0.287 \\ \text { Physical Load } & 310.10 & 1.423 & 0.157 \\ \mathrm{R}=0.018, \text { Adj. } \mathrm{R}=-0.001 . & \mathrm{F}(3,156)=0.973, \\ \mathrm{P} .=0.407 . & \end{array}$

Factor - Communication

$\begin{array}{lrrl}\text { Intercept } & 979.94 & 1.847 & 0.067 \\ \text { Tell New Emp. } & -377.91 & -0.551 & 0.583 \\ \text { Tell Current E. }-235.39 & -1.019 & 0.310 \\ \text { Sign Form } & 225.30 & 0.249 & 0.804 \\ \text { Rel. w/ Doctors } & 79.83 & 0.080 & 0.936 \\ \text { R }=0.014, \text { Adj. R } \mathrm{R}=-0.013 . & \mathrm{F}(4,148)=0.529, \\ \mathrm{P} .=0.715 .\end{array}$

Factor - Non-ERTW Approach

$\begin{array}{lrrl}\text { Intercept } & 324.37 & 0.399 & 0.691 \\ \text { Training } & -387.07 & -1.421 & 0.158 \\ \text { Company Call } & 282.70 & 0.371 & 0.711 \\ \text { Work w/ worker } & 532.82 & 0.655 & 0.514 \\ & & & \\ \mathrm{R}=0.014, \text { Adj. } \mathrm{R}=-0.006 . & \mathrm{F}(3,148)=0.716, \\ \mathrm{P} .=0.544 .\end{array}$


TABLE XII

A COMPARISON OF HIGH VERSUS LOW PERFORMING ORGANIZATIONS ON WAGE REIMBURSEMENT COSTS

Variable

High Performers

Low Performers

Written Policy

Yes

498

$56 \%$

No

$51 \%$

448

ERTW

$\begin{array}{ll}\text { Yes } & 908 * \\ \text { No } & 108\end{array}$

$768 *$

448

Written Program

Yes

468

328 *

No

548

688

Tell New Employees

Yes

No

458

378 *

558

638

Tell Current Employees
Before Injury
After Injury
$718 *$
498
298
$51 \%$

Sign Form

$\begin{array}{ll}\text { Yes } & 17 \% \text { * } \\ \text { No } & 838\end{array}$

88 *

928

Supervisor Involved

Sometimes/Never

Usually/Always

$718 *$

298

698 *

318

Not Exceed Drs. Orders

Yes 788 *

708 *

No

228

308 
TABLE XII

A COMPARISON OF HIGH VERSUS LOW PERFORMING ORGANIZATIONS ON WAGE REIMBURSEMENT COSTS (Continued)

Variable

Low Performers

Training

Moderate/Extensive $\quad 698 *$

A Little/None 318

518

498

Relationships w/ Drs.

Positive

$158 *$

58 *

No Comment

838

958

Negative

28

08

Prefer to Wait

At Least Sometimes 228*

No

788

308 *

708

Use Light Duty

Yes

$958 *$

No

58

908 *

108

\& Cases Lt. Duty Used

$\begin{array}{lcc}76-1008 & 708 * & 458 \\ 758 \text { or less } & 258 & 428 \\ 08 & 58 & 138\end{array}$

Use Regular Wage

Yes 898*

718

No

118

298

Empl. Must Call Co.

Yes

$738 *$

278

$748 *$

No

268

Co. Calls Dr.

Yes

788 *

228

$718 *$

No

298

Work w/ Injured Worker

Yes 88\%*

808 *

No

128

208

Physical Load Written Most/All 
TABLE XII

A COMPARISON OF HIGH VERSUS LOW PERFORMING ORGANIZATIONS ON WAGE REIMBURSEMENT COSTS (Continued)

\section{Variable}

High Performers

Low Performers

Level of Dedication

$\begin{array}{ccc}5,4 & 838 * & 63 \% \\ 3,2,1 & 108 & 8 \% \\ \text { No Program } & 78 & 178\end{array}$

Note - * = significant trend at the 0.05 level. 
TABLE XIII

\section{A COMPARISON OF HIGH VERSUS LOW PERFORMING ORGANIZATIONS ON MEDICAL COSTS}

Written Policy

Yes

No

568

448

618

398

ERTW

$$
\begin{aligned}
& \text { Yes } \\
& \text { No }
\end{aligned}
$$

$908 *$

108

$85 \%$ *

158

Written Program

Yes

$59 \%$

418

458

No

398

618

398

Yes

No

668

348

$70 \%$ *

$30 \%$

Sign Form

$$
\text { Yes }
$$

No

158 *

858

$128 *$

888

Supervisor Involved

Sometimes/Never

Usually/Always

$328 *$

$68 \%$

28 용 *

728

Not Exceed Drs. Orders

$$
\text { Yes }
$$

No
$758 *$

258 
TABLE XIII

A COMPARISON OF HIGH VERSUS LOW PERFORMING ORGANIZATIONS ON MEDICAL COSTS

(Continued)

Variable

High Performers

Low Performers

Training

Moderate/Extensive

598

608

A Little/None

418

408

Relationships w/ Drs.

$\begin{array}{ll}\text { Positive } & 10 \% \text { * } \\ \text { No Comment } & 80 \% \\ \text { Negative } & 10 \%\end{array}$

$38 *$

978

Negative

$10 \%$

08

Prefer to Wait

At Least Sometimes

$178 *$

$228 *$

No

838

788

Use Light Duty

Yes

No

8 Cases It. Duty Used

$$
\begin{aligned}
& 76-1008 \\
& 758 \text { or less } \\
& 08
\end{aligned}
$$

368

$3 \%$

Use Regular Wage

Yes

No

$928 *$

88

Empl. Must Call Co.

$$
\text { Yes }
$$

No

$768 *$

248

$78 \%$ *

228

No

Work w/ Injured Worker

$$
\text { Yes }
$$

$88 \%$ *

128
818 *

198

$938 *$

78

638

308

78

$75 \%$ *

258

$758 *$

258

Physical Load Written

Most/A11

Some/None 
TABLE XIII

A COMPARISON OF HIGH VERSUS LOW PERFORMING ORGANIZATIONS ON MEDICAL COSTS

(Continued)

\begin{tabular}{cccc} 
Variable & High Performers & Low Performers \\
\hline Level of Dedication & & \\
5,4 & $778 *$ & $818 *$ \\
$3,2,1$ & 188 & 78 \\
No Program & 58 & 128 \\
\hline
\end{tabular}

Note $-*=$ significant trend at the 0.05 level. 


\section{DISCUSSION}

Because of the exploratory nature of this research project, the following findings must be viewed as tentative. However, the lack of previous research in this area also means that the findings discussed here can provide a much needed source of direction for further research on ERTW programs.

\section{DESCRIPTIVE FINDINGS}

The survey revealed that of those firms with over 50 employees in the Portland Metropolitan area (which were selected because they had at least a reasonable likelihood of having some on-the-job injuries), almost half reported having an ERTW program, and nearly all reported using light duty at least some of the time. Of those organizations who sometimes use light duty for injured employees, well over two thirds use it for 768 to 1008 of eligible injuries. In addition, 798 of respondents rated their organization's level of dedication to their ERTW program as a 4 or 5 on a scale of 1 to 5 , where 5 was "extremely dedicated". These findings strongly suggest that ERTW programs have become a widely accepted way of doing business.

However, a substantial portion of the organizations surveyed $(188)$, reported that they would prefer to wait 
until the injured employee was completely recovered before returning that person to work in at least some cases. Not all of these organizations explained their reasons for this preference, but for those who did, it frequently involved fear of reinjury, fear of liability, or not having productive positions to put the injured employee in. Additionally, 218 of the organizations use light duty or modified work for less than $25 \%$ of the eligible cases. Further, $14 \%$ reported that they do not work with the injured employee to help get them back to work. Almost one third of the organizations reported that no one had any training on ERTW programs. The above findings suggest that there is still a good-sized minority of organizations who are not using ERTW programs very much, and would likely benefit from education about the advantages of such programs.

The survey also revealed some information about how ERTW programs are being designed in the organizations that have chosen to embrace them. Two of the most popular features involve working with the injured employees to help them return to work and assigning the supervisors the responsibility to assure that the injured employees do not exceed their doctor's prescribed limitations in physical activity. Having the employee contact the company regularly while off work was also a frequent feature, although some respondents reported that while it was a requirement, it was not regularly enforced. An equally popular approach involved having someone contact the medical provider to 
ascertain the status of the injured employee and in some cases to encourage the doctor to consider light duty or modified work as an option. One ERTW option which seems to be greatly under-utilized is that of having the employees sign a form stating that they understand and accept the ERTW program. Only a small minority of the organizations with ERTW programs use this strategy, despite the fact that it is highly recommended by SAIF, and has the ability to carry legal power and can help the organization to control fraudulent claims. Another somewhat under utilized approach involves analysis and written documentation of the physical load demands of various positions in an organization. Almost one-third of the survey respondents reported that their organization did not use this tactic. The major benefit is that it can help the attending physician to understand the demands of a position and accurately assess the injured employee's readiness for it. This applies whether light duty is used or not. A few firms reported using videotape technology to give the physician a complete understanding of exactly what a light or modified duty position would involve. Those who reported using this approach felt that it was extremely effective.

\section{EXPLORATORY FACTOR ANALYSIS FINDINGS}

The outcome of the factor analysis provided some of the most interesting results. Factor analysis of data collected in the survey resulted in a five factor solution. Factor 
one involved organizations that took a non-ERTW approach to dealing with injured employees. The activities which loaded on this factor were 1 ) working with the injured employee to get them back to work, 2) calling the medical provider to determine when the injured employee would be able to return to work, 3) lowering the employees wage if they did light duty or modified work, and 4) obtaining training about ERTW. (However, the regular wage variable did not load on this factor in the confirmatory factor analysis, but instead broke out into a single-indicator factor). Because none of these activities involve active ERTW, this factor was interpreted as an approach to dealing with injured workers that largely does not include ERTW. While training on ERTW may seem to be an active approach (and may assist an organization in an organizations' attempts to implement an ERTW program), it is not evidence of any active commitment to the ERTW approach.

Factor two involved organizations' perceptions of ERTW programs. The activities that loaded highly on this factor involved 1) reporting that the organization has an ERTW program, 2) involving the injured employees supervisor in ERTW decisions, and 3) making the supervisor responsible for assuring that the doctors' prescribed physical limitations were adhered to by the injured employee. Several other variables also had high loadings on this factor, but had higher loadings on another factor. These activities likely play a role in organizations' perceptions of ERTW programs, 
but are more highly associated with other things. Those activities were obtaining training about ERTW, offering regular wage to injured employees who are working in light duty or modified work positions, and creating written descriptions of the physical demands of their various positions.

Factor three involved the extent of organizations ERTW programs. The activities which loaded highly on this factor were 1) using light duty and 2) with a tendency to use it in as many cases of injury as possible, and 3) having the employee call the organization to keep in contact during the time they were unable to work due to their injury. In addition, these organizations had two attitudes in common 4) they strongly prefer to bring the injured employee back to work even before $s /$ he is 1008 recovered (with medical approval and supervision), and 5) they express a high level of dedication to using ERTW. All of these activities and attitudes demonstrate an active use of and commitment to ERTW .

Factor four involved organizations' level of communication about their ERTW program. The activities which loaded highly on this factor involved 1) telling new employees about the program, 2) informing current employees about the program before an injury took place, 3) asking employees to sign a form stating that they understand the ERTW program and agree to abide by it, and 4) having good relationships with the treating physicians. While it is 
possible to have a strong ERTW program without these factors, the existence of them is believed to make the program more usable.

Factor five involved the written formalization of an organizations programs and policies for dealing with an injured employee. The activities which loaded highly on it involved 1) having a written policy for dealing with injured employees, 2) having a written ERTW program, and 3) having written descriptions of the physical demands of the various positions in the organization. An additional factor analysis which included outcome data from the state of Oregon Bureau of Labor and Industries revealed that their outcome variables could be understood in terms of two underlying factors. The first one involved the people statistics. Variables which loaded highly on it were the number of currently open cases, the number of non-disabling cases for the year, and the number of reopened cases for the year. The other factor involved the dollars outcomes - the costs of medical treatment for the injury and the cost of wage reimbursement.

\section{CONFIRMATORY FACTOR ANALYSIS FINDINGS}

Confirmatory factor analysis of the above results (without data from the State of Oregon Bureau of Labor and Industries) on a separate hold-out sample revealed that these factor structures were reasonably stable. These findings suggest that the results could be used as a 
starting point in future research, providing a model for understanding the factors that make up ERTW programs.

Confirmatory factor analysis was also done for the nine factor model. Two additional single-indicator factors were hypothesized - they involved the ERTW program variable and the regular wage variable. The data from the state of Oregon Bureau of Labor and Industries was also used. Two factors, the first involving people statistics regarding workers' compensation and the second involving dollars outcomes of workers' compensation claims. The findings of this analysis were quite stable, indicating that the ninefactor model may provide future researchers with an strong base from which to move forward. This model not only provides an outline of the factors that make up ERTW programs, but also offers an understanding of the factors that make up organizational outcomes. However, it does not offer an understanding of where outcome variables such as average days lost per claim and number and costs of disabling claims may fit with other outcome variables.

Future work in the structural modeling arena should include the identified factors. However, more variation is needed to give the ERTW program and policy variables stronger predictive power. It may also be useful to move to a nonparametric approach to modeling the effect of ERTW programs and policies on organizational workers' compensation outcomes. In addition, future researchers should strive to obtain data on the average number of days 
lost per injury and on the number of permanently disabling claims. The inclusion of these variables will give a model the opportunity to examine a larger universe of outcomes and may be the variables for which ERTW programs have the greatest effect.

\section{REGRESSION FINDINGS}

The results of the regression analysis suggest that the components of the programs which this survey examined do have a moderate ability to predict change in workers' compensation medical costs over a five-year period. The variables that contributed significantly to the model were using regular wage for employees on light duty, having written descriptions of the physical demands of the various job positions, and having a high level of dedication to the ERTW program. Each of these variables was associated with better performance on the change in medical costs over time. This analysis sheds some light on one of the most serious critisisms of ERTW - the concern that the use of ERTW may cause reinjury to the injured worker. Because the analysis does not reveal any relationship between using ERTW and increased medical costs, it does not support these concerns. In fact, the relationship between ERTW and decreasing medical costs suggest that ERTW may be healthier for the injured employee than staying home during recovery.

All of the variables together also had a significant ability to predict the change in wage reimbursement costs 
over time. The variables that contributed significantly to the model were having a written return-to-work policy and using regular wage for employees on light duty. Both of these variables were associated with better performance on the change in medical costs over time.

The survey variables that had significant, simple correlations with the change in medical costs and wage reimbursement costs over the five year period from 1985 to 1990 also give some indication about to which components of ERTW programs might be especially important. Several variables were significantly related to change in medical costs over time. Those respondents who reported that their organizations preferred to wait until the injured employee was fully recovered to return them to work had significantly higher medical costs, which may result because most or all of the physical improvement needed for the worker to reach full performance level occurred under direct medical supervision, not through work hardening done while doing doctor-approved light duty or modified work. Althernatively, these findings may be a result of the psychological benefits of staying active in the workforce. Those organizations who used ERTW and paid regular wage to employees while they were on light duty, those who were more dedicated to their ERTW programs, and those who involved the supervisor in decision making had lower medical costs than those who did not do the above things. Only two variables had significant, simple correlations with the change in 
median wage reimbursement costs. Organizations who prefer to wait until the injured employee is fully recovered before returning them to work have higher wage reimbursement costs and organizations with higher levels of deciation to their ERTW programs have lower wage reimbusement costs.

\section{FINDINGS ON THE COMPARISON OF HIGH VERSUS LOW PERFORMING ORGANIZATIONS}

Surprisingly, while there were major differences in the variables that affected medical and wage reimbursement costs in previous analyses, the results of this analysis were very similar for these two variables. These similarities occurred despite the fact that only approximately 508 of the companies that were top performers on change in median medical costs were also top performers for change in median wage reimbursement costs. In addition, the same amount of overlap - approximately 508 - was found between those companies who were poor performers for change in median medical costs and those who were poor performers on change in median wage reimbursement costs. The comparison suggested that the simple existence of an ERTW program did not increase an organizations chances of being a high performer. In addition, high and low performing organizations did not differ in their use of two very popular features - supervisory involvement in decision making about the injured worker and giving the supervisor responsibility for assuring that the injured worker not 
exceed the doctors' prescribed physical limitations. However, high performers on both variables used light duty more often and were more dedicated to their ERTW program. High-performing organizations also preferred to pay regular wage when employees were on light duty rather than applying some other wage to light duty hours. Poor-performing organizations tended to prefer not to tell their new employees about their ERTW program and those who showed the worst performance on change in wage reimbursement costs tended to prefer not to put their ERTW programs in writing. Overall, high performing organizations appear to have a higher level of commitment to their ERTW programs.

\section{LIMITATIONS OF THIS STUDY}

There are a number of limitations of this study. First, it is based on correlations, not on any form of experimental intervention, which means that no causal conclusions can be reached based on the results. Second, the inability to obtain data on the state of organizations' programs and policies five years ago means that we are simply operating on the assumption that their programs and policies have improved (from the point of view of ERTW) during that time. Third, the inability to obtain data from the state of Oregon on the average number of days lost per claim for each organization and on the number of permanently disabling injuries and their associated costs drastically limits the ability to draw conclusions on the effectiveness of 
organizations policies and practices. Finally, this study may lack statistical power. There were few organizations that were using all components of ERTW programs or who had truly complete programs in effect. These are the organizations for which the greatest change in costs should be found. A larger sample size with stratified sampling based on program completeness would improve the power of the study

\section{PROBLEMS WITH THE SURVEY INSTRUMENT}

In assessing the percentage of injuries in which ERTW was used by an organization, we created four categories instead of using the actual estimated percentage. This was done in case some survey respondents had difficulty estimating this number and would be more able to estimate it in terms of broad ranges. However, it is possible that this method of treating the data seriously undermined the predictive strength of this variable. It also drastically decreased the scale variation, which forces a larger amount of error into the model when attempting to predict variation in variables (such as the medical and wage reimbursement costs) with much larger scales. In addition, the wording of this question "What proportion of the employees have light duty or modified work available?" - needs to be refined. The idea behind it was to assess the proportion of cases in which light duty was used in comparison to the proportion of cases in which it could have been used. The wording used 
frequently required some explanation and the question was generally answered in terms of the percentage of injuries in which ERTW was used. Changing the scales might also help normalize the distribution of responses.

The scale for assessing the level of dedication to the organization's ERTW program also needs to be improved. It might be worthwhile to ask separate questions about the level of dedication among top managers and the level of dedication among supervisors. It would also be useful to broaden the scale, either by expanding it to at least a 1 to 10 scale and providing specified anchors for each point, or by using an estimate of the percentage of each group that is dedicated to the program. Alternatively, the percentage of people with no, low, medium, high, and very high levels of dedication could be assessed.

Another question which could be made more specific is that assessing the level of training on ERTW programs. There are at least three distinct groups of people who are of interest here. They are top managers, supervisors, and those people who administer the workers' compensation program. The level of training each group has had should be assessed separately to examine the separate effects of training at different organizational levels on the outcome variables. In addition, the effectiveness of different sources of training could be assessed, as training can come from insurers, medical care providers, the state of Oregon, rehabilitation facilities, and so on. 
Because the possible importance of the organizations' relationships with the treating physicians was not anticipated, no question specifically addressed that topic. Instead, it was an issue that was raised by a number of organizations in a general question on whether there was anything else that they felt was important. If we had assessed each organization's relationship with the treating physicians, we would have obtained a better indication of the importance of this variable. A four or five point scale should be created for this variable, with a response category for those organizations who have no relationship with the treating physicians and a response category for those organizations whose relationships with the treating physicians vary widely. While it is not possible to be certain of the importance or meaning of this variable, preliminary indications suggest that poor (and sometimes adversarial) relationships tend to occur when the care providers are not educated about the concept and benefits of ERTW while good relationships tend to occur when the care providers are very familiar with the physical demands of the positions in the organizations and the way in which the organization treats the injured employee.

Yet another survey issue which came up during this research is that those organizations which say that they do not have an ERTW program may still use light duty or modified work for at least some portion of their injured workers. This means that to have or not have an ERTW 
program does not completely distinguish between users and non-users of the major mechanism of ERTW programs. However, it is not known what meaningful differences exist between the two approaches.

One variable of ERTW programs which was not included in the survey was that of whether the organization used only modified positions or was willing to "make up" positions to be able to provide light duty. For those organizations who do not have many ERTW modified positions, the acceptance of "make-work" may be an important factor in their ability to use ERTW as often as is optimal. Another variable which might provide interesting data is whether the organization has any difficulty getting injured employees to return to their regular jobs. Several organizations mentioned experiencing this problem, and it could potentially affect their wage reimbursement costs.

\section{RECOMMENDATIONS FOR FURTHER RESEARCH}

Further research should include using the average number of days lost per injury as an outcome variable. This is vital, as it is the variable which is most likely to be directly affected by ERTW programs. It will likely serve as a medicating variable between the percent of cases in which light duty is used and the median wage reimbusement costs. A second concern with the outcome variables used in this study was the confound between size of organization and the "number of..." variables. This concern could be addressed 
by partialling out organizational size. It will also be important for future research to examine permanently disabling injuries since this category of injuries often results in either large settlements or long-term payments. On the questionnaire side of the research, any future modeling efforts should not be done with such limited scales - the process of gathering information on the programs and policies relating to injured workers must incorporate scales with the largest possible (meaningful) variance. It may also be necessary to move to a nonparametric approach to deal more effectively with the non-normal variable distributions, although larger, more accurate scales and larger sample sizes may normalize the distributions somewhat. Additional modifications to the questionnaire that may prove fruitful involve examining the accuracy of organizations' perceptions of their level of dedication to their ERTW programs in relation to their actual level of sophistication. General observations from the telephone surveys suggest that those organizations with poor programs tend to over-rate their organizations level of dedication, while organizations with good programs tend to be quite realistic about their level of dedication. Examining the level of dedication to various components of the ERTW program may be a useful approach to examining this question. In addition, an index of organizations' sophistication level in using ERTW would need to be created. Unfortunately, the exploratory research accomplished in this study does not yet 
provide sufficient knowledge to enable a reasonable index to be created.

The ideal research method for studying the effect of ERTW programs would utilize a longitudinal design with data collected on the organizations' policies and practices at more than one point in time. Changes in programs and policies over time could then be related to changes in the outcomes experienced by the organizations.

Finally, becuase the variables examined were only able to account for a moderate amount of variance in the change in either medical or wage reimbusement costs over time, it will be important to examine other variables which may affect these outcomes. There are several variables which may prove to offer some explanatory power. One of these is the effect of the employee who may serve as a mediating variable between the organization's culture and outcome variables or as a separate variable in itself. Another variable that should be examined is the organization'safety program which may affect not only the number of injuries, but also the severity of those injuries.

The prevalence of the role of regular wage in all of the analyises suggest a need to better understand what affects this variable and what may be affected by it. It is possible that the decision regarding regular wage may be an indicator of a cluster of things involving managerial approach . 


\section{RECOMMENDATIONS FOR ORGANIZATIONS}

The following recommendations are based on the findings discussed above. However, because the research is exploratory, they should only be used as guidelines, not hard and fast rules. There were several variables that appear to be particularly important in terms of organizational outcomes based on both the regression analysis and the binomial analysis. They are using regular wage for employees who are injured but are doing light duty or modified work, using ERTW in as large a percentage of cases as possible (with doctors' approval), and increasing the level of dedication to the ERTW program. The apparent effect of using regular wage, as opposed to some lower wage for light duty hours worked may be due to motivational effects - that is, an employee who is still experiencing some level of pain and disability may work harder to overcome those things when $s /$ he has the opportunity to maintain their usual standard of living. The importance of the percentage of cases in which light duty is used is not surprising. An ERTW program will likely have a cumulative effect based on the number of cases in which it is applied. It may also have a positive effect on employees morale if they see it being used regularly. In addition, consistent use of ERTW is likely to work as a deterrent to those few employees who might otherwise file fraudulent claims. The importance of the level of dedication variable suggests that 
those persons interviewed in the survey - the people who knew the most about how the organization dealt with injured workers were handled in an organization - understand their organizations' level of dedication with some level of accuracy. This conclusion was reached during the phone interviews when the researcher noted that respondents from organizations with sophisticated ERTW programs tended to make estimates of dedication consistent with her own informal estimate, while respondents from organizations with unsophisticated ERTW programs tended to rate their organizations much higher than her informal rating. It may therefore be useful to involve those people in any planning on how to increase the level of dedication within the organization.

In addition, no component was found to be harmful to the organizational outcomes studied, which suggests that adding any component should not produce adverse effects on organizational outcomes. 


\section{REFERENCES}

Bollen, K. (1989). Structural Equations with Latent Variables. NY, NY: Wiley and Sons.

Brown, G. (1990, April 9). Outlook gloomy for workers comp. Journal of Commerce $\underline{\alpha}$ Commercial, $384,9 \mathrm{~A}$.

Hakstian, A. R., Rogers, W. T., \& Catell, R. B. (1982). Some notes on the number of factors problem. Multivariate Behavioral Research, 17, 193-219.

Hansen-Mayer, T. (1984). The worker's disability syndrome. Journal of Rehabilitation, 50, 50-54.

Hood, L., \& Downs, J. (1985). Return-to-work: $\underline{A}$ literature review. (Report No. TMF - P003 - 5). Topeka, KS: The Menniger Foundation.

Kelvin, P. (1981). Work as a source of identity: The implications of unemployment. British Journal of Guidance $\underline{\&}$ Counseling, $\underline{9}, 2-11$.

Livneh, H. (1982). On the origins of negative attitudes toward people with disabilities. Rehabilitation Literature, $43,338-347$ ).

Lucas, S. (1987). Putting a lid on Disability Costs. Management Solutions, $32,16-19$.

Mapes, J. (1990, January 7) . Workers' compensation: A system in pain. The sunday oregonian, pp. A1, A24.

SAIF Corporation. (1990). Early return to work programs get workers up and running. Compnews, January/February, p. 1-2.

SAIF Corporation (1990, June). Helping you reduce your workers' compensation claim costs: Early returnto-work programs. Brochure R322.

Treelsen, R. (1989) . Cutting workers' compensation costs: Return to work programs for injured workers. Presented at the American Trucking Association Regional Safety Meeting, Sparks, Nevada, May 2, 1989. 
U.S. Social Security Administration. (1987). Annual Statistical Supplement to the Social Security Bulletin.

Versluys, H. P. (1980). Physical rehabilitation and family dynamics. Rehabilitation Literature, 41, $58-65$.

Wardrop, R. (1984). Curing your company's health care headaches. Nation's Business, Jan, 50-51.

U.S. Department of Commerce, Economics and Statistics Administration, Bureau of Economic Analysis. (1991, July). Local area personal income 1984$\underline{1989}, \underline{5}$

U.S. Bureau of Labor Statistics. (1991, January). CPI detailed Report.

U.S. Department of Labor, Bureau of Labor Statistics. (1991, November). Employment and Wages, Annual Averages, 1990, 38, 83. Bulletin 2393. 
APPENDIX

SURVEY QUESTIONNAIRE 
Return To Work Policy Questionnaire

Hi. My name is Lorrie Riat. I'm doing a survey under the direction of Dr. Nancy Perrin at Portland State University. We're interested in looking at different types of return to work programs for injured workers. could you answer a few questions for us?

Company Name

Number of employees $\mathrm{W} / \mathrm{C}$ Insurer

Official Job Title Is Co. Unionized

Number of Lost Time Injuries in Last Year

Average Time Lost Due to Injury

1. Do you presently have a written return-to-work policy?

Yes No

2. Do you presently have an early-return-to-work program?

Yes No (IF NO, GO TO 11)

For those WITH early return to work programs:

3. Do you have a written procedure describing who takes what steps and when in the process of getting an injured employee back to work?

Yes No

4. Is there a mechanism within your company for informing people when they're hired about your earlyreturn-to-work program?

Yes No

5. Is there a mechanism within your company for informing current employees about your early-return-towork program?

All are Informed

Most are Informed

Only Some are Aware

Usually Find Out After an Injury 
6. Are your employees required to sign a form indicating that they understand and accept your earlyreturn-to-work policy?

Yes No

7. Are 1 ine supervisors involved in early-return-towork decisions for employees they supervise?
Always
Usual1y
Sometimes
Never

8. Is there someone who makes sure that an employee on modified work does not exceed the physical limitations set by their doctor?

Yes No

9. Has anyone in your organization received any training, either formal or informal, on early-return-to work-programs?
Extensive
Moderate
A little
None

10. Are there any other components of your early-returnto-work program that you feel either contribute to or hinder the success of the program? Yes No yes, describe)

11. Does the organization prefer to wait until the injured employee is fully recovered before returning them to work?

Yes Sometimes No

12. Does the organization provide light duty or modified work for the injured worker?

Yes No (If NO, GO TO 15)

13. In what percentage of the cases of injury (excluding minor injuries) is light duty or modified work used?
A. Under $25 \%$
B. 258 to 498
C. 508 to 758
D. 768 to 1008 
14. If an employee is on light duty, do they collect their regular status wage?

Yes No

15. When an employee is out of work due to an injury, are they required to contact the company at regular intervals?

Yes No

16. Is there an individual in your company who contacts medical providers to discuss when an injured employee can return to work?

Yes No

17. Is there an individual in your company who works with the injured employee to get them back on the job?

Yes No

18. Do you have detailed job analyses of worker physical load for each of your job categories?

Yes No

If YES, what is the occupational title of the person who did that work?

IF company has early return to work program OR lightduty/modified work:

19. Overall, how dedicated do you feel your company is to using early-return-to-work on a scale of 1 to 5, where 5 is extremely dedicated.

$$
\begin{array}{lllll}
1 & 2 & 3 & 4 & 5
\end{array}
$$

Thank you for taking the time to answer this survey. 